\title{
The behavioral economics of currency unions: Economic integration and monetary policy
}

\author{
Akvile Bertasiute $^{\mathrm{a}}$, Domenico Massaro ${ }^{\mathrm{b}, \mathrm{d}}$, Matthias Weber ${ }^{\mathrm{c}, *}$ \\ a Euromonitor International, Lithuania \\ ${ }^{\mathrm{b}}$ Department of Economics and Finance, Università Cattolica del Sacro Cuore, Italy \\ ' School of Finance, University of St. Gallen, Switzerland \\ d Complexity Lab in Economics, Italy
}

\section{A R T I C L E I N F O}

\section{Article history:}

Received 28 February 2019

Revised 16 January 2020

Accepted 21 January 2020

Available online 30 January 2020

\section{JEL classification:}

E70

F45

E52

D84

\section{Keywords:}

Behavioral macroeconomics

Monetary union

Currency union

Determinacy of equilibria

Reinforcement learning

\begin{abstract}
A B S T R A C T
We analyze different behavioral models of expectation formation in a multi-country New Keynesian currency union model. Our analyses yield the following robust results. First, economic integration is of crucial importance for the stability of the economic dynamics in a currency union. Second, when the economic dynamics are unstable, more activist monetary policy does not lead to stable economic dynamics. These findings have natural counterparts in the rational expectations version of the model: there, economic integration is crucial for the determinacy of the equilibrium and when the equilibrium is indeterminate, more activist monetary policy does not lead to a determinate equilibrium. In an application to euro area data, we find that the behavioral macroeconomic model outperforms its rational counterpart in terms of prediction performance.
\end{abstract}

(c) 2020 The Author(s). Published by Elsevier B.V. This is an open access article under the CC BY license.

(http://creativecommons.org/licenses/by/4.0/)

\section{Introduction}

The economics of currency unions is of great importance. The euro area is the world's largest currency union, making up for more than 15 percent of nominal world GDP, but it is not the only large currency union: many African countries, for example, share a common currency, the CFA franc. However, compared with the vast amount of economic research conducted on closed economies, research on currency unions is still relatively sparse. In particular, very few studies analyze currency unions from the perspective of behavioral economics, deviating from full rationality.

\footnotetext{
We thank an associate editor, two referees, Mariarosaria Comunale, Anh Dinh Minh Nguyen, Cars Hommes, Simas Kucinskas, Kostas Mavromatis, Lucas Radke, Timo Reinelt, and Jonas Striaukas for comments and suggestions, furthermore participants of the 2nd Behavioral Macroeconomics Workshop in Bamberg, the ZEW Public Finance Conference in Mannheim, the BEAM-ABEE Workshop in Amsterdam, the Inaugural Baltic Economic Conference in Vilnius, the Baltic Central Bank Meeting in Vilnius, the WEAI meetings in San Diego, and seminar participants at GATE Lyon, Vilnius University, Stockholm School of Economics in Riga, the Bank of Lithuania, and ISM University Vilnius. Domenico Massaro acknowledges financial support from the Ministry of Education, Universities and Research of Italy (MIUR), program SIR (grant n. RBSI144KWH). Part of this research was conducted while Bertasiute and Weber were at the Bank of Lithuania.

* Corresponding author.

E-mail address: matthias.weber@unisg.ch (M. Weber).
} 
The standard assumption in macroeconomics that expectations are formed rationally is questionable. This assumption means that all agents in the economy know the exact theoretical relationships governing macroeconomic variables and that they are able to perform the mathematically involved computations leading to the equilibrium. This contradicts common sense, as well as a great deal of economic and psychological evidence that humans are not fully rational (accumulated at least since Tversky and Kahneman, 1974). While many scholars have already taken non-rational expectations in account when modeling closed economies (e.g., Evans and Honkapohja, 2006, Branch and McGough, 2009, Branch and McGough, 2010, De Grauwe, 2010; De Grauwe, 2011; De Grauwe, 2012a; De Grauwe, 2012b, Branch and Evans, 2011, Kurz et al., 2013, Massaro, 2013, Pfajfar and Zakelj, 2014, Hommes et al., 2019), international macroeconomics still focuses almost exclusively on rational expectations (notable exceptions providing two-country models with deviations from rational expectations are Torój, 2010, De Grauwe and Ji, 2017, Kobielarz, 2017, and Bonam and Goy, 2019).

We present the first multi-country New Keynesian currency union model with behavioral expectations. We use different versions of behavioral expectations, reaching from a simple homogeneous adaptive rule to a more sophisticated behavioral reinforcement learning model that was developed over a long series of research projects (e.g., Hommes et al., 2005b; Anufriev and Hommes, 2012). The latter assumes that agents use different heuristics, such as a rule extrapolating trends or a rule assuming that trends are important in the short run while variables return to an anchor in the long run, and that agents switch between these heuristics depending on how well the heuristics have predicted economic variables in the recent past. The simple models of expectation formation have the advantage that they make a straightforward analysis of the local stability of the steady state possible. The sophisticated model has the advantage that it is built on micro data and describes actual human behavior well in a variety of settings; this comes at the expense of having to rely on simulations for the analysis of stability.

The different versions of behavioral expectations all lead to the following two main results. First, the stability of the economic dynamics in a currency union depends crucially on the level of economic integration. More economic integration leads to more stable economic dynamics. This is so as higher economic integration (more trade between the countries) renders the countercyclical effects of the real exchange rate more important, thereby supporting countries in a bust while dampening inflation and output gap in countries in a boom (that is, the countercyclical effect that a change in the countries' competitiveness has is more effective in stabilizing the economies when the countries are economically more integrated). Second, if the economic dynamics in a currency union are unstable, the central bank cannot stabilize the currency union with more active monetary policy. This is so because the central bank can only react to currency union aggregates; it cannot conduct different monetary policies in different countries. The interest rate it sets will, thus, always be too high for some countries and too low for others. Our findings from the behavioral models correspond naturally to a similar analysis of the fully rational version of the model. There, high economic integration is necessary for the equilibrium to be determinate. Similarly, if there is an indeterminacy of equilibria, more activist monetary policy does not lead to a determinate equilibrium. Note that the level of economic integration needed for stability under the simple models of behavioral expectations and for determinacy under rational expectations increases with the number of countries in the currency union.

In an application to euro area data, we then compare the prediction performance of the behavioral macroeconomic model (employing the more sophisticated reinforcement learning model) to that of the rational version of the model. We find that the behavioral model predicts inflation and output gap one quarter ahead better than the rational benchmark.

This paper differs from the existing literature in the following ways. A major difference from the existing literature analyzing currency unions without assuming full rationality (Torój, 2010, De Grauwe and Ji, 2017, Kobielarz, 2017, and Bonam and Goy, 2019) is that all of the existing models are two-country models, while ours is a multi-country model. In addition, there are various other differences to this existing literature. Torój (2010) analyzes currency unions under a variety of homogeneous behavioral rules of expectation formation, in isolation and in half-half mixes with rational expectations. There is no switching between rules, and there is heterogeneity only in the cases in which half of the agents are fully rational. He shows that macroeconomic volatility is higher when expectations are not rational. The study furthermore shows that currency unions can exhibit unstable economic dynamics under behavioral expectations for a given calibration (without specifying how the stability depends on model parameters). De Grauwe and Ji (2017) provide interesting and intuitive aggregate equations but do not provide microfoundations for these. The focus of their study is to analyze the role of so-called animal spirits in the synchronization of business cycles. Kobielarz (2017) models a small country joining a large country to form a currency union. The focus of that paper lies on the small joining country. Expectations are formed via constant gain learning of the parameters of the model equations, which are correctly specified. Different initial conditions, representing a different history of economic variables before joining the currency union, may then hamper the convergence to the new steady state. In Bonam and Goy (2019), agents form expectations by performing a recursive least squares algorithm to estimate the parameters of the correctly specified model equations. However, agents have a home bias when performing these regressions, meaning that foreign variables receive less weight than in a regular least squares estimation. They find that combinations of Taylor rule parameters that lead to a determinate rational expectations equilibrium may not be a stable equilibrium when agents have home-biased expectations. This is the case, because the home bias in expectations strengthens the pro-cyclical effect of the real interest rate. Our paper also contributes to the rational expectations literature on currency unions. Our behavioral model is a version of the model by Galí and Monacelli (2005); to compare our analyses on economic integration and monetary policy, we also examine these in the rational expectations model. Our findings on how equilibrium determinacy depends on the level of economic integration and how monetary policy is ineffective when 
economic integration is too low are novel. Furthermore, the comparison of the behavioral model to the rational model in terms of prediction performance is novel.

Our research has the following policy implications. As economic integration is of crucial importance for the functioning of a currency union, policy makers should undertake reforms that strengthen economic ties between countries. However, such reforms may only bear fruit in the long run. As stabilization is also important in the short and medium run, monetary policy should not be the sole macroeconomic stabilization tool. One or more additional policy tools are required, since monetary policy is insufficient to stabilize the currency union (insufficient does not mean unimportant, as badly conducted monetary policy remains a potential source of trouble). The most natural candidate as stabilizing tool in the short and medium run is fiscal policy. Thus, fiscal policy should be made available for stabilization at the country level and not rendered inflexible by constitutional arrangements or multilateral agreements (although, agreements that allow for or require strong countercyclical fiscal policy may be useful). In addition, macro- and microprudential policies could be useful to make the dynamics of currency unions more stable, as they can reduce extreme booms and busts in the different member countries. The more countries there are in a currency union, the more important it is that additional stabilization tools are available (and that the countries are economically integrated).

This paper is organized as follows. Section 2 introduces the models of the macroeconomy and expectation formation. Section 3 contains the theoretical and simulation results and their interpretation. Section 4 contains an application of the model to euro area data. Section 5 discusses the policy implications of our analyses and concludes. The derivation of the microfoundations for the behavioral multi-country currency union model can be found in Appendix A.

\section{Macroeconomic model and expectation formation}

We first describe the macroeconomic model of the currency union. We present aggregate equations in the main text, while the microfoundations under behavioral expectations are derived in Appendix A (the microfoundations under homogeneous rational expectations can be found in Galí and Monacelli, 2005). Matrix forms of the systems of equations that are shown in this section can be found in Online Appendix B. After discussing the macroeconomic equations and briefly their relation to the microfoundations, we discuss the behavioral models of expectation formation and how they are used in the macroeconomic model.

\subsection{Currency union model}

We consider a currency union of $N$ countries and assume that the currency union does not interact with the rest of the world. The economic dynamics in the currency union can be described by the following equations:

$$
\begin{aligned}
& y_{t}^{i}=\bar{E}_{t}^{i} y_{t+1}^{i}-\frac{1}{\sigma}\left(r_{t}-\bar{E}_{t}^{i} \pi_{t+1}^{i}-\rho\right)+\gamma \bar{E}_{t}^{i} \Delta s_{t+1}^{i}+v_{t}^{i} \\
& \pi_{t}^{i}=\beta \bar{E}_{t}^{i} \pi_{t+1}^{i}+\kappa y_{t}^{i}+\xi_{t}^{i} \\
& r_{t}=\max \left\{\bar{\pi}+\rho+\Phi_{\pi}\left(\pi_{t}^{c u}-\bar{\pi}\right)+\Phi_{y}\left(y_{t}^{c u}-\bar{y}\right), 0\right\} .
\end{aligned}
$$

The superscript $i$ signifies that variables belong to country $i(i=1, \ldots, N) . y_{t}^{i}$ is the output gap in country $i$, $\pi_{t}^{i}$ is inflation in this country, and $r_{t}$ is the nominal interest rate, which is identical across countries. Expectations $\bar{E}_{t}^{i}$ are the average expectations of a future variable of the economic agents in country $i$ at time $t . \bar{E}_{t}^{i} y_{t+1}^{i}$ and $\bar{E}_{t}^{i} \pi_{t+1}^{i}$ are thus the average expectations (across economic agents of country $i$ ) of the future output gap and future inflation in this country, respectively. Expectations can be formed rationally or according to behavioral models. We assume that these expectations are formed with knowledge of all realizations up to time $t-1 . \sigma, \kappa, \gamma, \beta$, and $\rho:=-\log \beta$ are positive parameters. For simplicity, we consider homogeneous structural parameters across countries here, although these parameters can in general be different for different countries (in Section 4 we allow for heterogeneity in parameters across countries). $\Phi_{\pi}$, and $\Phi_{y}$ are positive parameters describing monetary policy, while $v_{t}^{i}$ and $\xi_{t}^{i}$ are random disturbances.

The superscript $c u$ signifies that variables are at the currency union level, so that $\pi_{t}^{c u}$ stands for inflation in the currency union, which is a weighted average of inflation at the country level. The weight $w(i)$ of country $i$ represents this country's economic importance, thus $\pi_{t}^{c u}=\frac{1}{\sum_{k=1}^{N} w(k)} \sum_{k=1}^{N} w(k) \pi_{t}^{k}$ and $y_{t}^{c u}=\frac{1}{\sum_{k=1}^{N} w(k)} \sum_{k=1}^{N} w(k) y_{t}^{k}$. The term $\bar{E}_{t}^{i} \Delta s_{t+1}^{i}$ denotes the expected change in the effective terms of trade of country $i$ with the rest of the currency union.

Eq. (1) is the dynamic IS equation. As in standard models of closed economies, the output gap depends on the average future expected output gap $\bar{E}_{t}^{i} y_{t+1}^{i}$, the real interest rate $r_{t}-\bar{E}_{t}^{i} \pi_{t+1}^{i}$, and a demand (or technology) shock $v_{t}^{i}$. Eq. (1) differs from a standard IS equation of a closed economy through the part $\gamma \bar{E}_{t}^{i} \Delta s_{t+1}^{i}$. This addition signifies that if prices are expected to rise more abroad than in country $i$, thus improving the competitiveness of country $i$, the output gap in country $i$ will be higher than it would be if equal rises of prices were expected (for positive $\gamma$ ). While it is in general not necessary for economic agents to know the macroeconomic model equations under behavioral expectations (in fact, as we argue when introducing behavioral expectation formation below, it is much more realistic that agents do not know all the equations governing the macroeconomic dynamics), we do assume that agents know the simple economic relationship between inflation 
and the real exchange rate (given that there is one currency, so that the nominal exchange rate is fixed), so that $\bar{E}_{t}^{i} \Delta s_{t+1}^{i}$ simplifies to $\bar{E}_{t}^{i} \pi_{t+1}^{* i}-\bar{E}_{t}^{i} \pi_{t+1}^{i}$, where $\pi^{* i}$ is the weighted average of inflation in all countries excluding country $i$. That is, in line with advanced and introductory textbooks, an expected change in the real exchange rate only reflects an expected change in the inflation differential.

Eq. (2) is the New Keynesian Phillips curve, which is similar to that in a closed economy. Here, inflation depends on average expected future inflation $\bar{E}_{t}^{i} \pi_{t+1}^{i}$, the current output gap, and a supply (or cost-push) shock $\xi_{t}^{i}$.

Eq. (3) describes the behavior of the central bank, which is a single central bank for the whole currency union. It sets the interest rate according to a Taylor rule, reacting to deviations of inflation from the inflation target $\bar{\pi}$ and deviations of the output gap from the steady state at the currency union level. The interest rate is subject to a zero lower bound.

In the steady state that is not at the zero lower bound, inflation in all countries is equal to the central bank's inflation target $\bar{\pi}$. The steady state of the output gap consistent with the inflation target is $\bar{y}=\frac{(1-\beta) \bar{\pi}}{\kappa}$.

\subsection{Relation of the aggregate equations to the microfoundations}

The derivation of the aggregate equations is based on two key hypotheses. The first is that we assume the law of iterated expectations to hold at the individual level. This is quite standard in the literature (see Evans and Honkapohja, 2001, Branch and McGough, 2009, and Kurz et al., 2013, among others) and it allows us to obtain individual consumption and pricing decisions that depend only on forecasts for time period $t+1$. Aggregating optimal decision rules derived in this way results, when compared to the benchmark model assuming homogeneous rational expectations, in two additional terms in the aggregate equations (see Kurz et al., 2013, and Hommes et al., 2019). In fact, the aggregate demand equation includes the difference between the average expectations of individual consumption and average consumption, while the aggregate supply equation includes the difference between the average expectations of individual price and average price.

The second hypothesis is that, on average, these differences are zero. This is obviously true in the homogeneous rational expectations benchmark but also under a variety of assumptions about agents' beliefs. As one example, Hommes and Lustenhouwer (2019) argue that, when agents are switching among different forecasting rules and know that the probability of adopting a certain rule is the same across individuals, expectations about future individual and aggregate consumption/price coincide. We also discuss other options that can lead to this assumption in Appendix A.

Note that the parameter $\gamma$ in the IS equation is in the microfoundations a composite parameter, depending on $\sigma$ and on the parameter determining trade openness, $\alpha$. To be precise, $\gamma=\frac{\alpha(1-\sigma+(1-\alpha)(1-\sigma))}{\sigma}$. Thus, for a given $\sigma, \gamma$ is just a function of $\alpha$. For the values of $\sigma$ that we consider most relevant, $\gamma$ is a monotonically increasing one-to-one mapping from [0,1], the interval on which $\alpha$ is defined, to an interval $[0, a]$. With the benchmark calibration that we use, $a=5.37$. We call $\gamma$ the parameter of economic integration to distinguish it from trade openness $\alpha$. It is natural that countries in a currency union are strongly economically integrated when they trade a lot with each other. We prefer to state results in terms of $\gamma$ rather than $\alpha$ to allow reading this article without delving into the microfoundations. ${ }^{1}$

\subsection{Expectation formation}

Assuming full rationality means assuming that all agents in an economy have a full understanding of how the economy functions (i.e., they know the equations governing the economy including its parametrization) and that all agents have the capacity to perform all necessary calculations to maximize expected discounted lifetime utility and form model-consistent expectations. This is unrealistic, and many studies in economics and psychology have documented boundedly rational behavior. $^{2}$ Specifically, a great deal of research has documented that expectations in macroeconomics and finance are not formed rationally (Blanchflower and MacCoille, 2009; Branch, 2004; Carroll, 2003; Cornea et al., 2019; Malmendier and Nagel, 2016; Pfajfar and Santoro, 2010). Instead, people use relatively simple heuristics to form expectations and forecast future economic variables. This does not mean that agents are "stupid"; using such heuristics can be considered a clever way of dealing with cognitive limitations (see Gigerenzer and Todd, 1999, or Gigerenzer and Selten, 2002).

In this paper, we rely on three variants of behavioral expectations. One is a simplistic adaptive model, one is a model of intermediate complexity (a very simple heuristic switching model), and the third is a full-fledged heuristic switching model. The first models have the advantage of analytical tractability, so that local stability analyses can be performed. The third has the advantage that it is a modern model that describes micro-behavior well in a variety of setting (this comes at the expense of analytical tractability when employed in the macroeconomic model). We first discuss the most sophisticated of these three models, the other two can then easily be introduced and understood.

The sophisticated benchmark model of expectation formation was developed over a long series of research projects (starting with Brock and Hommes, 1997, and Brock and Hommes, 1998; see Hommes, 2011, for a survey). Agents have a set of

\footnotetext{
1 We focus on calibrations leading to positive $\gamma$. Note, however, that $\gamma$ can also be negative. A negative $\gamma$ is similar to situations in which the MarshallLerner condition does not hold.

2 Since the early contributions of Tversky and Kahneman (1974) and Grether and Plott (1979), the literature has exploded and covers most aspects of economic life, from saving and consumption decisions (e.g., Thaler and Benartzi, 2004) over asset pricing (e.g., Weber et al., 2018) and reactions to taxes (e.g., Weber and Schram, 2017) to health-conducive and hazardous lifestyle choices (e.g., Richman, 2005).
} 
Table 1

Set of heuristics in the benchmark heuristic switching model.

\begin{tabular}{lll}
\hline ADA & adaptive expectations & $x_{1, t+1}^{e}=0.65 x_{t-1}+0.35 x_{1, t}^{e}$ \\
WTR & weak trend-following & $x_{2, t+1}^{e}=x_{t-1}+0.4\left(x_{t-1}-x_{t-2}\right)$ \\
STR & strong trend-following & $x_{3, t+1}^{e}=x_{t-1}+1.3\left(x_{t-1}-x_{t-2}\right)$ \\
LAA & learning, anchoring, and adjustment & $x_{4, t+1}^{e}=0.5\left(x_{t-1}^{a v}+x_{t-1}\right)+\left(x_{t-1}-x_{t-2}\right)$ \\
\hline
\end{tabular}

Notes: $x_{t-1}^{a v}$ denotes the average of all observations up to time $t-1$.

heuristics available and switch between them depending on how well these heuristics have performed in the recent past. Our description of this model here is similar to the description in Hommes et al. (2019).

In order to forecast a variable $x$, agents can make use of $H$ different heuristics. The set of available heuristics is denoted by $\Lambda$. A forecasting heuristic $h \in \Lambda$ can be described as

$$
x_{h, t+1}^{e}=f_{h}\left(x_{t-1}, x_{t-2} \ldots ; x_{h, t}^{e}, x_{h, t-1}^{e} \ldots\right) \text {. }
$$

In this paper, the variable $x$ represents either inflation $\pi$ or the output gap $y$. Note that the information available for forecasts of $x$ in period $t+1$ consists of the variable up to period $t-1$.

This framework allows for all sorts of heuristics, from extremely simple rules of thumb to complicated formulas. However, while agents may use relatively simple forecasting heuristics, the model assumes that agents learn from past mistakes. In short, agents switch between heuristics according to how well these have performed in the (recent) past. Such reinforcement learning precludes overly irrational behavior. The model thus makes use of a selection mechanism that steers which heuristics are chosen each period through an evolutionary fitness criterion. The fitness of forecasting heuristic $h$ is denoted by $U_{h}$ and defined as

$$
U_{h, t-1}=\eta U_{h, t-2}-F\left(x_{h, t-1}^{e}-x_{t-1}\right),
$$

where $F$ is a function of the distance of heuristic $h$ 's forecast from the actual realization, which we assume to be the squared error. $0 \leq \eta \leq 1$ measures the relative weight of errors in the more distant past and is called a memory parameter. If $\eta=0$, the fitness measure solely depends on the most recent observation. If $0<\eta<1$, the fitness measure depends on all past prediction errors with exponentially declining weights. If $\eta=1$, the fitness measure weights all past observations equally. Assuming that all agents update the heuristic they use each period, one can describe the probability that an agent uses heuristic $h$ in period $t$ (or similarly the fraction of agents using heuristic $h$ in period $t$ ) by

$$
n_{h, t}=\frac{\exp \left(\mu U_{h, t-1}\right)}{\sum_{h=1}^{H} \exp \left(\mu U_{h, t-1}\right)} .
$$

One can derive the multinomial logit expression described in Eq. (6) from a random utility model (see Brock and Hommes, 1997). $\mu \geq 0$ determines how likely it is that agents choose the optimal forecasting heuristic according to the fitness measure $U_{h}$. This parameter is called intensity of choice. If $\mu=0$, the fraction of agents choosing heuristic $h$ in period $t$, denoted by $n_{h, t}$, is constant, which means that agents do not react to past performance. If $\mu=\infty$, all agents always switch to the optimal forecasting heuristic according to the fitness measure.

The model described by Eq. (6) is extended in Hommes et al. (2005a) and Diks and van der Weide (2005). The extension allows for asynchronous updating, which means that it is possible that not all agents update the forecasting heuristic they use each period (this is consistent with empirical evidence; see Hommes et al., 2005b, and Anufriev and Hommes, 2012). One then arrives at a more general version of Eq. (6):

$$
n_{h, t}=\delta n_{h, t-1}+(1-\delta) \frac{\exp \left(\mu U_{h, t-1}\right)}{\sum_{h=1}^{H} \exp \left(\mu U_{h, t-1}\right)} .
$$

$0 \leq \delta \leq 1$ is the probability that an agent does not update the forecasting heuristic in a given period or, similarly, the fraction of individuals not updating their forecasting heuristic.

In general, the set $\Lambda$ can contain any number of heuristics. However, when applying the model, one set of forecasting heuristics needs to be specified. The set of heuristics that we use in the benchmark heuristic switching model is described in Table 1 . The switching model with these heuristics describes individual forecasting behavior well in a variety of settings. These include asset pricing models (Anufriev and Hommes, 2012; Hommes et al., 2005b; 2008) and macroeconomics models: in Assenza et al. (2019) and Hommes et al. (2019) this model explains output gap and inflation forecasts well in learning-to-forecast experiments based on a closed economy New Keynesian model. Following these papers, we use the calibration $\mu=0.4, \delta=0.9$, and $\eta=0.7$.

Note that there is evidence that evolutionary models of expectation formation describe survey data on inflation well (e.g., Branch, 2004, and Cornea et al., 2019). Moreover, (Cornand and Hubert, 2020) systematically compare inflation expectations in the field to those obtained in laboratory experiments and find that expectations in laboratory experiments behave very similarly to survey expectations. This provides additional support for our use of the switching model with the heuristics specified in Table 1. 
The two simple variations of behavioral expectations that we consider are as follows. The most basic model considers expectations to be formed according to the adaptive rule in Table 1 . There is no heterogeneity of expectations and consequently no switching between different rules. The intermediate model is a simplistic switching model without memory and without asynchronous updating $(\eta=\delta=0$; as in the behavioral benchmark model, $\mu$ equals 0.4$)$. In that model, agents have two heuristics available, one naive rule according to which the next forecast equals the last observation, $x_{1, t+1}^{e}=x_{t-1}$, and one trend-following rule with extrapolation coefficient one, $x_{2, t+1}^{e}=x_{t-1}+\left(x_{t-1}-x_{t-2}\right)$.

\subsection{Employing the behavioral models of expectation formation in the macroeconomic model}

We now move from the forecasting of a generic variable to the forecasting within the currency union model. The average expectation in country $i$ of the output gap in country $i$ is denoted by $\bar{E}_{t}^{i} y_{t+1}^{i}{ }^{3}$. These expectations can be written as $\bar{E}_{t}^{i} y_{t+1}^{i}=$ $\sum_{h=1}^{|\Lambda|} n_{h, t}^{y, i} y_{h, t+1}^{e, i}$, where the superscript $i$ in $n_{h, t}^{y, i}$ and $y_{h, t+1}^{e, i}$ denotes the country to which the fractions and the forecasting heuristics correspond (the superscript $y$ in $n_{h, t}^{y, i}$ indicates that the fractions when forecasting the output gap are in general different from the fractions when forecasting inflation). Inflation forecasts are similarly defined as $\bar{E}_{t}^{i} \pi_{t+1}^{i}=\sum_{h=1}^{|\Lambda|} n_{h, t}^{\pi, i} \pi_{h, t+1}^{e, i}$. In general $n_{h, t}^{y, i} \neq n_{h, t}^{y, j}$ and $n_{h, t}^{\pi, i} \neq n_{h, t}^{\pi, j}$ for $i \neq j$. Thus, the fractions used in the heuristic switching model are different for the forecasted variables in different countries.

The expectation terms $\bar{E}_{t}^{i} y_{t+1}^{i}$ in Eq. (1) and $\bar{E}_{t}^{i} \pi_{t+1}^{i}$ in Eq. (2) are average expectations of households in a country about a variable in the same country. However, Eq. (1) also contains expectations about foreign inflation, as $\bar{E}_{t}^{i} \Delta s_{t+1}^{i}=\bar{E}_{t}^{i} \pi_{t+1}^{* i}-$ $\bar{E}_{t}^{i} \pi_{t+1}^{i}$. Here, we assume that average expectations in country $i$ of inflation in country $j$ equal the average expectations of that variable in country $j$, so that

$$
\bar{E}_{t}^{i} \pi_{t+1}^{* i}=\frac{1}{\sum_{k \neq i} w(k)} \sum_{k \neq i} w(k) \bar{E}_{t}^{i} \pi_{t+1}^{k}=\frac{1}{\sum_{k \neq i} w(k)} \sum_{k \neq i} w(k) \bar{E}_{t}^{k} \pi_{t+1}^{k} .
$$

In general, it would of course be possible to introduce differences in expectations between $\bar{E}_{t}^{i} \pi_{t+1}^{k}$ and $\bar{E}_{t}^{k} \pi_{t+1}^{k}$. However, in this paper, we prefer to reduce the model to only $2 \mathrm{~N}$ different behavioral expectations (expectations of output gap and inflation in $N$ different countries). One could justify this assumption by thinking that agents form expectations only about variables in their own country, while accessing some information about aggregate expectations in other countries for expectations about other countries' variables (such as household expectation surveys or consumer confidence indices). ${ }^{4}$

\section{Results}

In this section, we first show the results on economic integration under the behavioral models of expectation formation and how these compare to the results under rational expectations. We then discuss the results on monetary policy, again first under behavioral expectations and then under rational expectations. ${ }^{5}$

We mainly resort to three symmetrical countries to have a simple illustration while still showing that our model is a multi-country model and not a two-country model (the general $\mathrm{N}$-country case is also interesting, as the level of economic integration needed for stability under behavioral expectations or determinacy under rational expectations depends on $N$ ). The default calibration that we use (unless otherwise stated) is $\beta=0.99, \kappa=0.001, \sigma=0.157$ (the value of $\gamma$ is discussed separately in the applications). The coefficients of the Taylor Rule are $\Phi_{\pi}=1.5$ and $\Phi_{y}=0.5$. The inflation target is $\bar{\pi}=0$. Our parameterization is in line with standard calibrations in the macro literature ${ }^{6}$ For the simulations of the full heuristic switching model, we initialize the model by starting out in the steady state (with an equal fraction of agents using each of the available heuristics). The error terms are independent and distributed according to a normal distribution with mean zero and standard deviation 0.1 for each of the three countries in the currency-union.

\subsection{Economic integration}

Economic integration (as represented by the parameter $\gamma$ or by trade openness $\alpha$ as discussed above) can play a crucial role for the stability of currency unions. While many deep model parameters may be hard to influence (it is, for example, completely unclear which reforms could alter $\sigma$ ), $\gamma$ can be influenced by reforms aimed at increasing or decreasing economic integration. We discuss such reforms in Section 5.

\footnotetext{
${ }^{3}$ With a continuum of households in country $i$, this means that $\bar{E}_{t}^{i} y_{t+1}^{i}=\int_{0}^{1} E_{j, t}^{i} y_{t+1}^{i} d j$, where $E_{j, t}^{i} y_{t+1}^{i}$ are the expectations about $y_{t+1}^{i}$ by household $j$ in country $i$.

${ }^{4}$ Note that our way of modeling is not the only possible one: Bonam and Goy, (2019) take a different route, assuming that agents in a country form (home-biased) expectations about all variables themselves, putting more weight on variables in their own country (in the regressions employed to form these expectations).

5 Our results also persist when expectations on a country's inflation and output gap are formed jointly with a bi-variate VAR( 1 ) process. We briefly treat this in Online Appendix B.2.4.

${ }^{6}$ The periods of the model can be interpreted as quarters and thus we follow the calibration of Woodford (1999) for $\beta$ and $\sigma$. The calibration of $\kappa$ follows Cornea et al. (2019) who estimate a New Keynesian Phillips Curve featuring heterogeneous expectations and a heuristic switching mechanism similar to the one described in Section 2.3.
} 

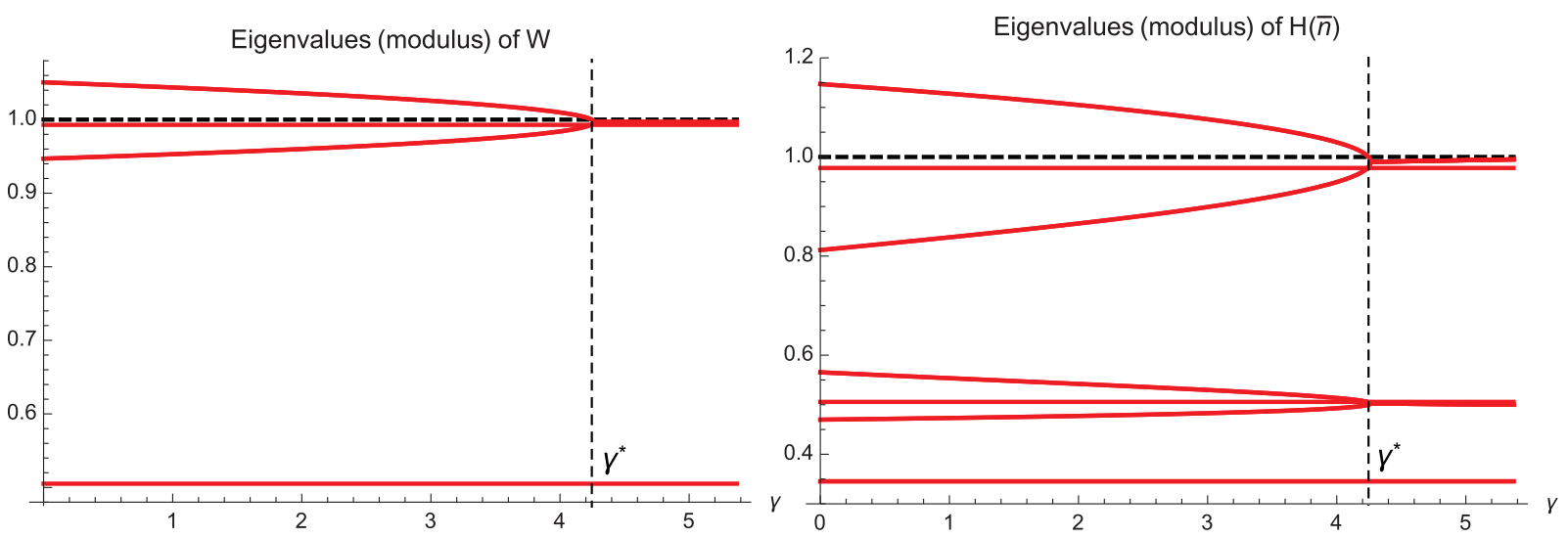

Fig. 1. Instability depending on $\gamma$. Notes: $\beta=0.99, \sigma=0.157, \kappa=0.001, \Phi_{\pi}=1.5, \Phi_{y}=0.5, N=3$. Parameter $\gamma$ is a convolution of the currency union's structural parameter $\sigma$ and the index of openness $\alpha \in[0,1]$. The range of $\gamma$ is thus obtained by letting $\alpha$ vary between 0 and 1 .

We start by studying the mathematical stability of the steady state as a function of the economic integration parameter $\gamma$ using the two simple versions of behavioral expectations as discussed in Section 2.3.

The first involves no switching between heuristics but assumes that expectations are formed homogeneously according to the specified adaptive rule. The second is the heuristic switching model where agents can only use two simple heuristics, namely naive expectations (naive expectations are expectations that always equal the last observations) and a simple trendfollowing rule with coefficient one. Moreover, the memory parameter $\eta$ and the inertia parameter $\delta$ are set to zero in this simple switching model. The rationale for analyzing these simpler models is that considering these simple models allows us to study the mathematical stability of the steady state analytically. The full four-heuristic heterogeneous expectations model presented in Section 2.3, although being characterized by a higher degree of behavioral realism, leads to a non-autonomous dynamical system that we analyze by means of simulations. We aim to describe the analysis in this section concisely, a more complete derivation and more details can be found in Online Appendix B.

The model for a currency union of $N$ countries can be written in matrix form as

$$
x_{t}=M x_{t+1}^{e}+R \epsilon_{t}
$$

where $x_{t}=\left(y_{t}^{1}, \ldots, y_{t}^{N}, \pi_{t}^{1}, \ldots, \pi_{t}^{N}\right)^{\prime}, x_{t+1}^{e}=\left(\bar{E}_{t}^{1} y_{t+1}^{1}, \ldots, \bar{E}_{t}^{N} y_{t+1}^{N}, \bar{E}_{t}^{1} \pi_{t+1}^{1}, \ldots, \bar{E}_{t}^{N} \pi_{t+1}^{N}\right)^{\prime}$ and $\epsilon_{t}=\left(v_{t}^{1}, \ldots, v_{t}^{N}, \xi_{t}^{1}, \ldots, \xi_{t}^{N}\right)^{\prime}$.

The stability properties of the model with homogeneous adaptive expectations (as described in Table 1) depend on the eigenvalues of the matrix $W=0.65 M+0.35 I$.

The local stability properties of the model featuring switching between naive expectations and the trend-following rule depend on the eigenvalues of matrix $H(\bar{n})$, defined as

$$
H(\bar{n})=\left(\begin{array}{cc}
F(\bar{n}) & G(\bar{n}) \\
I & 0
\end{array}\right),
$$

where $F(\bar{n})=M(I+\operatorname{diag}(1-\bar{n})), G(\bar{n})=-M \operatorname{diag}(1-\bar{n})$, and $\bar{n}$ is the vector of steady-state fractions of the naive rule (respectively, $1-\bar{n}$ is the vector of steady-state fractions of the trend-following rule). Given that the naive and the trendfollowing predictors deliver the same forecast in the steady state, $\bar{n}$ is equal to $1 / 2$.

In both cases the steady state is (locally) stable when all eigenvalues of the matrices $W$, or respectively $H(\bar{n})$, have modulus less than one. Fig. 1 shows the eigenvalues of matrices $W$ and $H(\bar{n})$ as functions of the economic integration parameter $\gamma$. The figure shows that the economic dynamics are stable only if $\gamma$ is greater than a threshold $\gamma^{*}$ (the precise value of $\gamma^{*}$ will be given in Eq. (10) below).

Moving to the fully fledged behavioral model, we can no longer analyze it with a local stability analysis. Therefore we resort to simulations of the model and a more pragmatic definition of stable economic dynamics, where we consider the dynamics as stable if there are no large deviations from the steady state. We consider two such measures, output gap instability and inflation instability. To be precise, we consider the simulation of one time series as exhibiting output gap instability if the average (across countries of the currency union) of absolute deviations of the output gap from the steady state is at least ten percent once. The second measure uses the same definition with inflation instead of the output gap. Note that these pragmatic definitions of unstable dynamics illustrate systematic deviations from the steady state rather than just shocks, as the shocks that we add to the model are much smaller than the $10 \%$ used in this measure of instability. Fig. 2 shows the instability of the economic dynamics for different values of $\gamma$. Each mark in the graph stems from 1000 simulations.

What can be seen, for the models with simpler expectation formation and for the fully fledged behavioral heuristic switching model, is that for low values of $\gamma$, that is, for a low level of economic integration, the economic dynamics in the currency union are unstable. When $\gamma$ increases, the economic system becomes stable. 


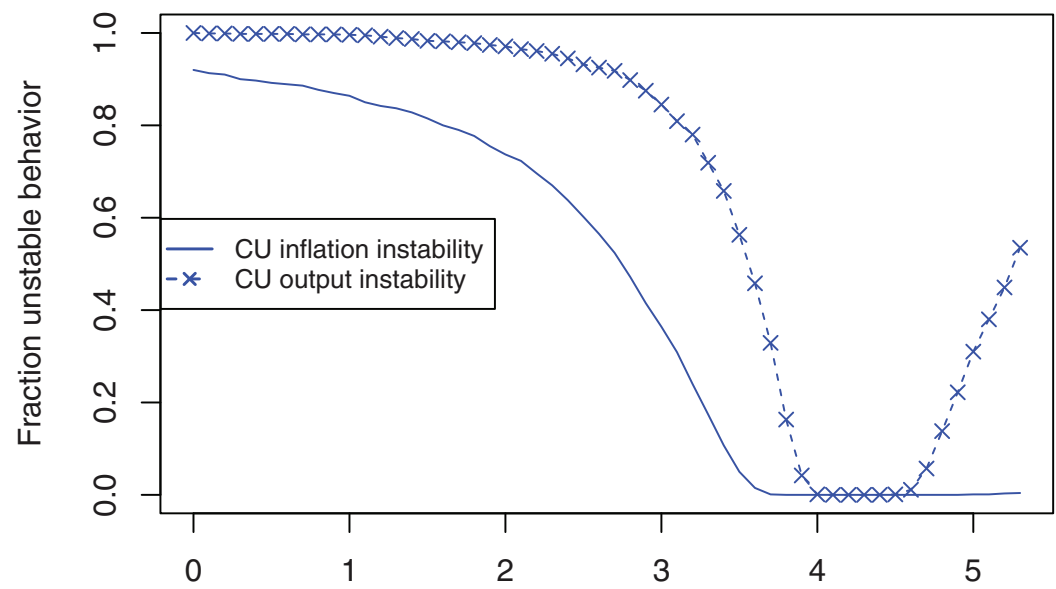

Fig. 2. Instability Depending on $\gamma$. Notes: $\sigma=0.157, \kappa=0.001, \beta=0.99, \Phi_{\pi}=1.5, \Phi_{y}=0.5$, sd $=0.1, N=3$. Parameter $\gamma$ is a convolution of the currency union's structural parameter $\sigma$ and the index of openness $\alpha \in[0,1]$. The range of $\gamma$ is thus obtained by letting $\alpha$ vary between 0 and 1 .

The stabilizing force of $\gamma$ is that when some countries are in a boom and others in a slump, expected increases in inflation in the boom countries lead to increased demand in the countries in a slump and vice versa, so that there exists a pull toward the steady state. This corresponds naturally to the intuition from basic classes on international macroeconomics: in a currency union (or fixed exchange rater regime), goods in countries in an economic downturn become relatively cheaper and will be thus imported to a greater extent by other countries. This stabilizing effect is stronger if the countries are more integrated economically. This effect is referred to as real-exchange-rate channel in the literature (e.g., Bonam and Goy, 2019).

Note that, for very high values of $\gamma$, output instability increases again for the fully-fledged heuristic switching model. For the maximal $\gamma$, the average of the absolute value of the output gap across countries exceeds $10 \%$ at least once in about half of the simulated currency unions. However, this arising instability seems to have little economic relevance, as the high values of $\gamma$ for which instabilities arise correspond to very high values of trade openness $\alpha$ (remember that the maximal $\gamma$ corresponds to $\alpha=1$ ), much higher than used in the literature (Bonam and Goy, 2019, and Kobielarz, 2017, for example, use $\alpha=0.25$ ). The intuition why very high values of $\gamma$ lead to such instabilities in the model is that such high values of $\gamma$ mean that output is influenced very much by inflation (deviations of inflation from the target in the currency union countries have thus very large effects on the output gap). However, the output gap in turn has comparatively little influence on inflation (because $\kappa$ is constant at 0.001 and does not increase with $\gamma$ ). A higher output gap then hardly raises inflation (increased inflation would decrease the output gap, via the interest rate). Output can then become unstable (for example with a significant fraction of agents using trend-following rules in the expectation formation) without enough opposing force. As noted above, though, we obtain this behavior for unrealistically high values of $\gamma$ and therefore interpret (with the above qualifying description in mind) also the results with the full behavioral model as more economic integration leading to more stable economic behavior.

The findings under the behavioral models of expectation formation have an interesting counterpart assuming rational expectations, which has (to the best of our knowledge) not been previously documented in the literature (in particular, this is not part of the work introducing the rational version of the macroeconomic model, Galí and Monacelli, 2005). We again keep the description brief here (more details can be found in Online Appendix B).

Determinacy under rational expectations is obtained when all eigenvalues of the matrix $M$ are within the unit circle. $M$ has $2 N$ eigenvalues. The absolute values of $2(N-1)$ eigenvalues depend on the economic integration parameter $\gamma$ and the number of countries in the currency union $N$ (as well as on the deep parameters $\beta, \kappa$ and $\sigma$ ) but do not depend on the monetary policy reaction coefficients $\Phi_{\pi}$ and $\Phi_{y}$. On the other hand, the absolute values of 2 eigenvalues depend on the monetary policy reaction coefficients $\Phi_{\pi}$ and $\Phi_{y}$ (as well as on the deep parameters $\beta, \kappa$ and $\sigma$ ) but do not depend on the economic integration parameter $\gamma$ and the number of countries in the currency union $N$.

The eigenvalues that depend on monetary policy are the same eigenvalues of a closed economy, that is as for Eqs. (1)-(3) with $\gamma=0$ and $N=1$. As it is well known, determinacy in a closed economy is obtained when monetary policy reaction coefficients satisfy the following condition:

$$
\kappa\left(\Phi_{\pi}-1\right)+(1-\beta) \Phi_{y}>0
$$

Assuming that monetary policy satisfies condition (9), the equilibrium's determinacy thus depends on the eigenvalues that depend on $\gamma$. Fig. 3 displays the eigenvalues of matrix $M$ as functions of the economic integration parameter $\gamma$ for a currency union with $N=3$. 


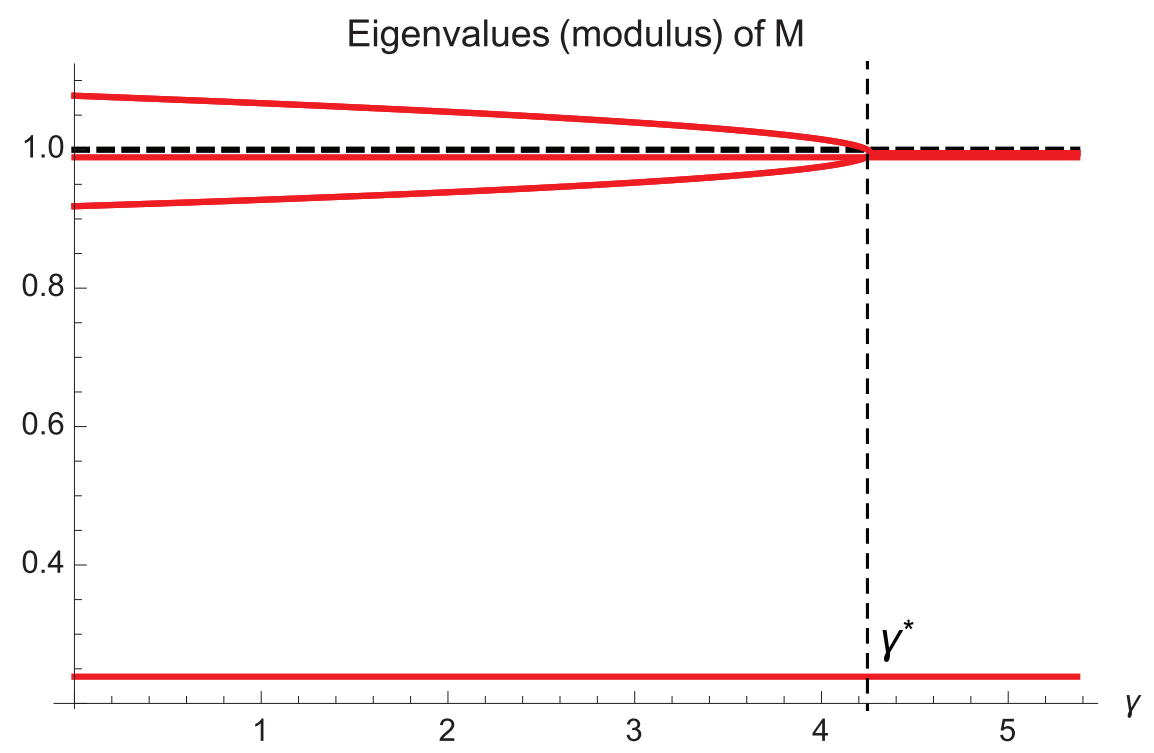

Fig. 3. Determinacy depending on $\gamma$. Notes: $\beta=0.99, \sigma=0.157, \kappa=0.001, \Phi_{\pi}=1.5, \Phi_{y}=0.5, N=3$. Parameter $\gamma$ is a convolution of the currency union's structural parameter $\sigma$ and the index of openness $\alpha \in[0,1]$. The range of $\gamma$ is thus obtained by letting $\alpha$ vary between 0 and 1 .

The largest of the eigenvalues of matrix $M$ that depend on the economic integration parameter $\gamma$ is equal to one for $\gamma=\gamma^{*}$, with

$$
\gamma^{*}:=(N-1) /(N \sigma)
$$

The equilibrium is thus determinate under rational expectations for $\gamma>\gamma^{*}$. This is exactly the same condition needed under both simple behavioral models of expectation formation for the steady state to be locally stable (this is discussed in detail in Online Appendix B). The value of $\gamma^{*}$ in the three country version shown in the graphs is about 4.2, corresponding to an $\alpha$ of about 0.53 .

\subsection{Monetary policy}

One might think that monetary policy can stabilize the economic dynamics in a currency union significantly. In particular, one might think that a stronger reaction of monetary policy to inflation (or the output gap) could be stabilizing. ${ }^{7}$ Thus, if the economic dynamics are unstable, because economic integration is too low, one might think that more activist monetary policy can lead to stable economic behavior. This is not the case, however.

As in the previous section, we first study the mathematical stability of the steady state for the simpler behavioral models (homogeneous adaptive expectations and the simple switching model with naive expectations and trend-followers). Then we analyze our main behavioral model by means of simulations. Fig. 4 displays the eigenvalues of the matrices $W$ and $H(\bar{n})$ as functions of the monetary policy reaction coefficient $\Phi_{\pi}$ (we obtain similar results when varying the reaction coefficient $\left.\Phi_{y}\right)$.

Both panels of Fig. 4 have been obtained with $\gamma=1$, that is, with a level of economic integration leading to instability in both models. As can be seen in both panels of Fig. 4, the unstable eigenvalue is not affected by monetary policy, meaning that monetary policy alone has no stabilizing power when the level of economic integration is too low.

Fig. 5 shows a similar result with simulations for our main behavioral model with the same calibration. It can be seen that more activist monetary policy does not make the economic dynamics more stable.

The reason for this is that the central bank can only react to currency union aggregates. This means that monetary policy is "wrong" for most, usually even for all, countries. Imagine a currency union where two countries have output gaps and inflation below the steady state, and one country has an output gap and inflation above the steady state, in a way that the currency union aggregates are exactly at the steady states. The interest rate is then too high for the two countries with low output gaps and inflation, potentially leading to a further decrease of these variables. The interest rate is too low, however, for the country in a boom, which may then exhibit further increases of output gap and inflation. This effect can be called a (pro-cyclical) real interest rate channel (cf. Bonam and Goy, 2019). Note that the results are not due to the lower bound on the interest rate: conducting simulations without the lower bound does not alter our conclusions.

\footnotetext{
7 As shown in model Eq. (3), we only consider a Taylor Rule as monetary policy. Other forms of conducting monetary policy, such as quantitative easing, are not considered. However, as discussed below, the important point is not the exact specification of the monetary policy rule, but the property that the central bank can only react to currency union aggregates with its monetary policy.
} 

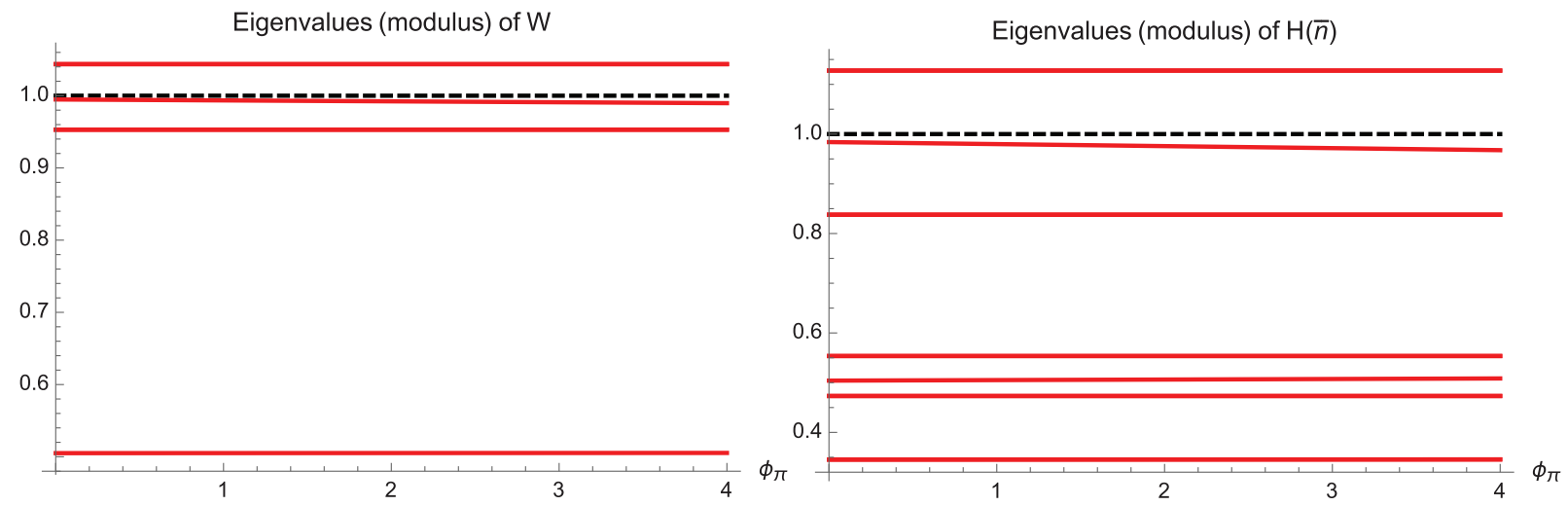

Fig. 4. Instability depending on $\Phi_{\pi}$ for unstable $\gamma$. Notes: $\beta=0.99, \sigma=0.157, \kappa=0.001, \Phi_{y}=0.5, \gamma=1, N=3$.

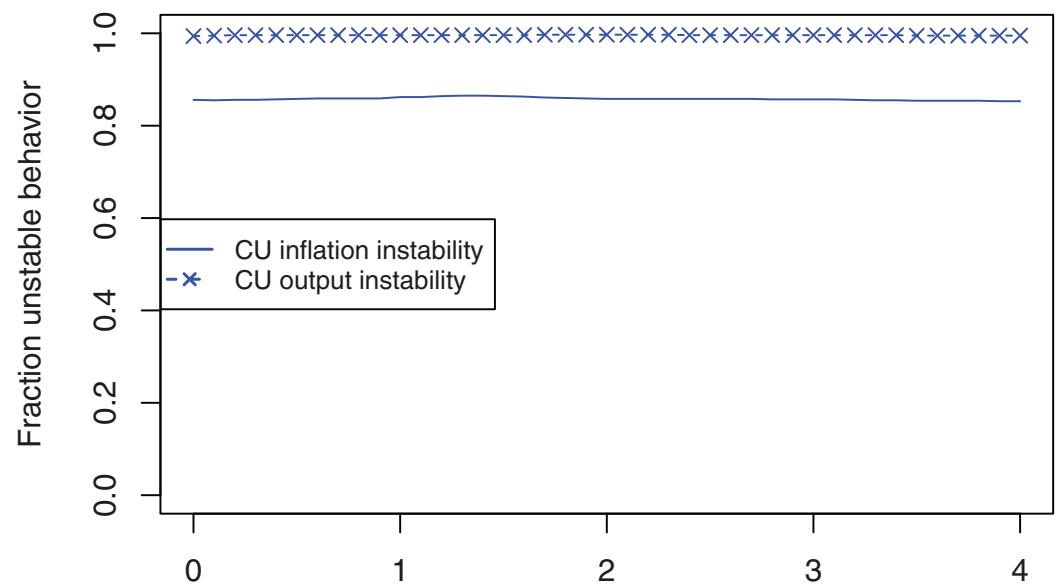

Fig. 5. Instability depending on $\Phi_{\pi}$ for unstable $\gamma$. Notes: $\sigma=0.157, \kappa=0.001, \beta=0.99, \gamma=1, \Phi_{y}=0.5$, sd=0.1, $N=3$.

That the inability of the currency union central bank to react to country-level variables is really responsible for the instability can be verified by conducting simulations of the same model but with monetary policy available at the country level. For these simulations, Eqs. (1) and (2) remain in place (except for a change of $r_{t}$ to $r_{t}^{i}$ in Eq. (1), reflecting the fact that interest rates can now differ across countries). The monetary policy Eq. (3) is replaced by $N$ equations of monetary policy, one for each country, of the form

$$
r_{t}^{i}=\max \left\{\bar{\pi}+\rho+\Phi_{\pi}\left(\pi_{t}^{i}-\bar{\pi}\right)+\Phi_{y}\left(y_{t}^{i}-\bar{y}\right), 0\right\} .
$$

We call such a model an artificial fixed exchange rate regime (artificial, because the central bank can freely choose monetary policy with a Taylor rule without any worries about the nominal exchange rate, which always remains fixed as in a currency union). One could say that in such an artificial fixed exchange rate regime the real interest rate channel is shut down. Fig. 6 shows economic instability for the full behavioral model. As can be seen, the economic dynamics are extremely stable in such a case (even for very low values of $\Phi_{\pi}$; the output stabilization through $\Phi_{y}$ and the limited stabilization from economic integration $\gamma$ are already enough to lead to stable economic dynamics).

Again, a counterpart of the behavioral findings exists with rational expectations that has not been documented before. As mentioned above, two eigenvalues depend on monetary policy but not on $\gamma$. If $\gamma$ is relatively high, the equilibrium is determinate if and only if monetary policy satisfies the Taylor principle. However, if $\gamma$ is low, the equilibrium will always be indeterminate, independent of the policy stance. This can be seen in Fig. 7, showing graphs that look very similar to those in Fig. 4.

\section{Empirical application}

The results in the previous section are similar for the different models of expectation formation. While this shows that the results and the resulting policy implications are robust across different ways of expectation formation, one may question whether it is necessary to look at multiple different ways of expectation formation. In particular, proponents of fully rational models may even believe that it is unnecessary to add realism to the model by using a behavioral model of expec- 


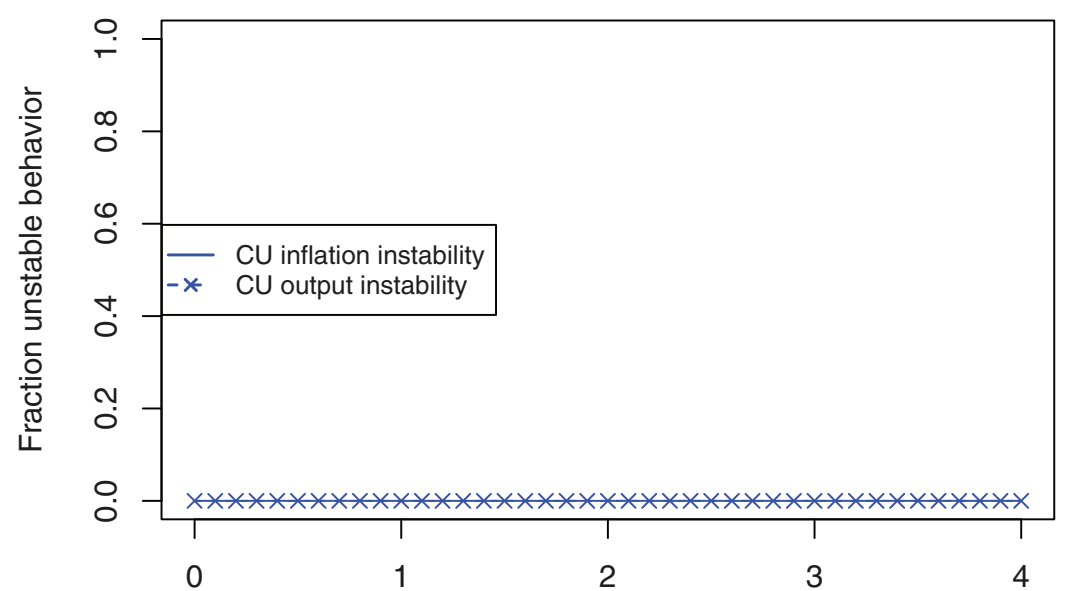

Fig. 6. Instability in the artificial fixed exchange rate regime in dependence of monetary policy parameter $\Phi_{\pi}$ for unstable $\gamma$. Notes: $\sigma=0.157, \kappa=0.001$, $\beta=0.99, \gamma=1, \Phi_{y}=0.5, \mathrm{sd}=0.1, N=3$.

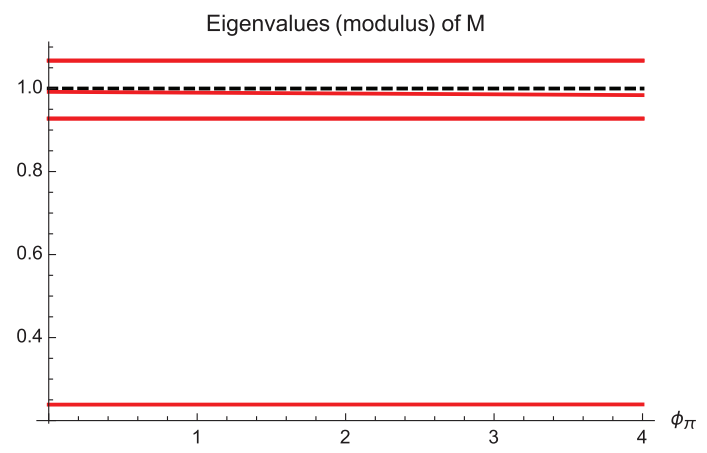

Fig. 7. Determinacy depending on $\Phi_{\pi}$. Notes: $\beta=0.99, \sigma=0.157, \kappa=0.001, \Phi_{y}=0.5, \gamma=1, N=3$.

Table 2

Parameter values.

\begin{tabular}{llll}
\hline & $1 / \sigma$ & $\kappa$ & $\gamma$ \\
\hline Austria & 0.02 & 0.16 & 0.01 \\
Belgium & 0.04 & 0.20 & 0.01 \\
Finland & 0.14 & 0.08 & -0.01 \\
France & 0.01 & 0.12 & 0.01 \\
Germany & 0.01 & 0.08 & 0.00 \\
Italy & 0.03 & 0.01 & 0.00 \\
Netherlands & 0.03 & 0.01 & 0.01 \\
Spain & 0.01 & 0.12 & 0.00 \\
\hline
\end{tabular}

Notes: Parameter values are annualized values derived from Dees et al. (2010). The values are rounded to the second decimal position.

tation formation (e.g., a model based on micro-evidence, such as the full reinforcement learning model with four heuristics). However, we believe that this still adds value. One way of assessing whether a model is better than another is to assess the prediction performance. This is what we try to touch upon in this section. Note, however, that a full-fledged empirical analysis is beyond the scope of this paper. Therefore, we do not attempt to estimate our own sets of parameters, or to compare the models to alternative specifications (adding frictions, habit formation, etc.), we merely check the prediction performance of the behavioral currency union model and its rational counterpart, with a fixed set of parameters obtained from the literature.

\subsection{Calibration and data}

Table 2 shows the set of parameter values that we use. The table shows $1 / \sigma, \kappa$, and $\gamma$ as estimated in Dees et al. (2010) for all countries that are (1) among the 12 countries that first introduced the euro, and (2) part of the set 
Table 3

Prediction mean squared errors.

\begin{tabular}{|c|c|c|c|c|c|c|c|c|}
\hline & \multicolumn{4}{|c|}{ 4-country model } & \multicolumn{4}{|c|}{ 8-country model } \\
\hline & \multicolumn{2}{|c|}{ Behavioral } & \multicolumn{2}{|c|}{ Rational } & \multicolumn{2}{|c|}{ Behavioral } & \multicolumn{2}{|c|}{ Rational } \\
\hline & $\pi$ & $y$ & $\pi$ & $y$ & $\pi$ & $y$ & $\pi$ & $y$ \\
\hline Austria & & & & & 0.21 & 0.96 & 0.72 & 2.11 \\
\hline Belgium & & & & & 0.39 & 0.20 & 1.54 & 1.08 \\
\hline Finland & & & & & 0.23 & 1.78 & 1.20 & 5.16 \\
\hline France & 0.22 & 0.17 & 0.79 & 1.12 & 0.22 & 0.17 & 0.79 & 1.12 \\
\hline Germany & 0.23 & 0.66 & 0.77 & 3.23 & 0.23 & 0.66 & 0.77 & 3.23 \\
\hline Italy & 0.24 & 0.27 & 1.00 & 2.10 & 0.24 & 0.27 & 1.00 & 2.10 \\
\hline Netherlands & & & & & 0.37 & 0.30 & 1.73 & 2.07 \\
\hline Spain & 0.57 & 0.07 & 2.40 & 1.60 & 0.57 & 0.07 & 2.40 & 1.60 \\
\hline Weighted average & 0.28 & 0.36 & 1.05 & 2.19 & 0.29 & 0.40 & 1.11 & 2.19 \\
\hline
\end{tabular}

Notes: The table contains mean squared errors of one-quarter-ahead predictions of inflation and output gap by the full behavioral model and the rational version of the model. Lower values imply better prediction performance.

of countries for which (Dees et al., 2010) estimate the parameters. ${ }^{8}$ The other parameter values that we use are $\beta=0.99$, $\Phi_{\pi}=1.5$, and $\Phi_{y}=0$ (we use $\Phi_{y}=0$, as the ECB has a mandate solely focusing on price stability; considering strictly positive values of $\Phi_{y}$ does not alter our conclusions). The country weights are determined by real GDP (using the average value across the time span that we consider). For the behavioral model (we only consider the full reinforcement learning model), we use the same parameter values as otherwise in the paper. ${ }^{9}$

The data we use reach from 1999:Q1, the beginning of the euro as an accounting currency, to 2014:Q4. We do not consider data after 2014:Q4 as those data would fall into the time of the ECB's asset purchase program. The interest rate may thereafter thus no longer be a good measure of the conducted monetary policy. All data is at quarterly frequency. The data we use for inflation is HICP data from the ECB (year-on-year percentage changes; therefore, no seasonal adjustment is necessary). The interest rate is the ECB rate on main refinancing operations (in percentages per annum). The data on the output gap stems from Comunale (2015); it is based on seasonally adjusted IMF IFS data on real GDP. The output gap is then calculated as the difference of the time series to a filtered series (using a one-sided HP filter with smoothing parameter 1,600 , as usually suggested for quarterly data). More details are available in Comunale (2015). All of the data we use are publicly available. ${ }^{10}$

\subsection{Prediction performance}

We compare the prediction performance by measuring the mean squared error of one-quarter-ahead predictions. The calibration of the parameters remains fixed throughout, but in the behavioral model, the fraction of employed heuristics evolves over time. We initialize the behavioral model in 1999:Q1 with an equal fraction of agents using each heuristic and update this fraction over time. The model then calculates the expectations of the variables at time point $t+1$ (in quarters) with all information until $t-1$ available. The model prediction of the variables at time point $t$ are then the realizations of the macroeconomic model in period $t$ stemming from the expectations of variables at $t+1$ (without any noise terms added). As only information up to period $t-1$ is used to calculate the model predictions in period $t$, these are (pseudo) out-of-sample forecasts. As the calibration of all parameters is fixed to pre-specified values, there are no degrees of freedom and the comparison to rational expectations is fair from this point of view.

Table 3 shows the prediction performance via the mean squared errors for the one-quarter-ahead predictions. We use a relatively sparse four-country model, consisting of the four largest euro area economies, and an eight-country model with all countries for which we have parameter estimates. The mean squared errors are given for the variables at the country level and at the currency union level (which is just a weighted average of the countries). The first two years of data (1999:Q12000:Q4) were excluded for the calculation of the mean squared errors, because this is the time when the behavioral model is being initialized (including those data does not alter our conclusions).

\footnotetext{
${ }^{8}$ Note that we adjusted the parameters to be used with annualized values rather than quarterly values (to be able to use year-on-year changes of inflation and the usual interest rate given in percentages per annum as inputs). As we require strictly positive values for $1 / \sigma$ and $\kappa$, we set the (relatively few) negative or zero values from the estimations to 0.01 (for annualized data).

${ }^{9}$ Note that the parameters as estimated by Dees et al. (2010) are not fully compatible with the microfoundations. In particular, the estimates of $\gamma$, together with the estimates of $\sigma$, regularly correspond to values of $\alpha$ that are outside the interval $[0,1]$. We allow for this inconsistency, but we provide a robustness check with the following specification. Instead of relying on the estimates of $\gamma$, we calculate values for $\gamma$ with the estimates of $\sigma$ and proxies for $\alpha$. These proxies for $\alpha$ are the averages of the export-to-GDP and import-to-GDP ratios (obtained with Eurostat data for the year 2008). These values are much larger in absolute terms than the values from Dees et al. (2010). Also with that specification, the behavioral model performs considerably better than the rational model (by about the same margin). The calibration and results of this robustness check can be found in Online Appendix B.4.

10 We subtract two (as the ECB's implicit inflation target) from the data on inflation and the interest rate, as well as from the lower bound, to be consistent with our model with a zero-inflation steady state.
} 
We can observe that both in the four-country and in the eight-country case, the behavioral version of the model predicts much better than its rational counterpart. This holds for inflation and output gap in all countries and, as a consequence, also for the weighted average of these errors (the weights for the weighted averages are defined as above, that is, using average real GDP across the time span of our sample).

\section{Policy implications and concluding remarks}

The policy implications of our paper arise from our two main findings. First, economic integration is important for stable economic dynamics (while this may be the healthy intuition of many economists working on currency unions, we provide a dynamic modeling framework to explain it). Note that the level of economic integration that is needed for stable economic behavior in a currency union increases with the number of countries in the currency union. Second, more activist monetary policy alone is insufficient to stabilize the economic dynamics in a currency union.

Turning first to economic integration, note that the most important factor determining economic integration is trade openness. Thus, policies that increase trade openness are favorable. Reforms could be aimed at removing obstacles to trade between the countries, or they could aim to ensure that firms from each country can compete in all countries. There are a variety of such policy measures. An essential basis is probably having a customs union (which is a natural predecessor of a currency union: it is questionable whether it is reasonable at all to have a currency union without a customs union). Further policy measures to increase economic integration are more subtle but still have the potential to be useful. The recent EU geoblocking regulation prohibiting discrimination against consumers and (partially) against businesses based on their location when buying goods or services could be seen as such a useful policy. Another potential regulation could oblige firms (probably only above a certain size) that offer to ship goods within their country of origin to ship to all countries of the union. One may even think of promoting the online presence in other languages or in one common language, so that consumers can more easily compare prices and buy goods and services abroad (this language could, in the case of the European Union, be English or even a language that is not the language of any member state, such as Esperanto; we admit that the costs and benefits of introducing such a policy are unclear). These reforms may not have a strong effect in the short run, but in the long run they could prove helpful.

The second part of the policy implications stems from the fact that more stabilization tools are needed in the short to medium run, because monetary policy alone is not enough to stabilize a troubled currency union (this does not mean that monetary policy is irrelevant: the central bank still needs to appropriately react to currency union aggregates, as poor interest rate decisions can cause problems). The most natural candidate for this is fiscal policy, as fiscal policy is available at the country level. Activist fiscal policy is not part of our model and therefore we can only speculate what arrangements to use fiscal policy for stabilization would be most effective. What should be guaranteed is that fiscal policy acts countercyclically; that is, it should be expansionary in an economic downturn and contractionary when a country's economy is doing well. Whether such countercyclical policy is then based on rules at the currency union level or implemented in the different countries independently, is on first sight irrelevant. However, we believe that rules at the currency union level make it much more likely that the fiscal policies are indeed countercyclical. Without such rules at the union level, politicians may be tempted to overspend in a boom for political reasons (or in some cases even to underspend in a downturn because of national regulation prohibiting debt). Beneficial fiscal rules applying to all countries would thus be very different from the low-debt rules that are currently in place, because the current rules are not countercyclical.

Fiscal policy may be the most flexible tool for business cycle stabilization, but it is not the only policy that may help to overcome the reduced power of monetary policy in a currency union. Macro- and microprudential policies may also be helpful. Any policy smoothing the economic dynamics in the member countries should be helpful for the stability of the union as a whole. Requirements to have relatively high down payments when taking up a mortgage to buy a house may reduce the size of housing bubbles, which influence the business cycle. Similarly, higher capital requirements for banks (potentially even with a countercyclical component) could reduce banks' risk-taking and the systemic risk arising from potential bank failures, which could help to flatten the credit business cycle.

Despite the fact that behavioral and rational expectations yield similar policy implications in our case, it does make a difference whether one uses behavioral or rational expectations in the economic models. This can be seen in the empirical application to euro area data that we provide, in which we compare the prediction performance of the behavioral currency union model (with the four-heuristic reinforcement learning model) to that of the rational version. Inflation and output gap predictions one quarter ahead from the behavioral model are considerably more accurate than those from the rational model.

Work in behavioral macroeconomics sometimes prompts the question whether or how the Lucas critique applies. The Lucas critique argues that it is important to build macroeconomic models based on individual human behavior. Humans can change their behavior in response to a policy change, therefore aggregate empirical relationships that have been observed in the past do not necessarily hold after a policy change. However, as our model is microfounded, the aggregate relationships that we use do arise from individual human behavior. With the simple model of homogeneous adaptive expectations, one may argue that human behavior is modeled as too stiff; one may claim that it does not adequately reflect changes in human behavior when the observations that people make change (for example because of a shift in policy). However, this is not the case for the full behavioral switching model, where agents are smart and choose their heuristics based on the evolutionary performance of these rules. Note also that, while rational expectations make it impossible that the government exploits the 
irrationality of economic agents, this does not have to hold true in the real world: there is no physical law stating that governments can under no circumstances exploit the irrationality of economic agents (for its own benefit or to increase social welfare; in fact, some nudges provide examples of governments making use of the irrationality of economic agents to increase social welfare). What should be a criterion for macroeconomic models, in our opinion, is that it should not be too easy for the government to exploit the irrationality of agents. The full behavioral switching model satisfies this requirement: agents choose their forecasting heuristics based on past performance and the set of available heuristics contains trendfollowing rules. If a central bank were, for example, tempted to conduct too loose monetary policy in the long run, this would lead to a pressure on inflation and thereby to more trend-following behavior, so that agents would expect a further increase in inflation (a feature not present under homogeneous adaptive expectations).

\section{Appendix A. Microfoundations of the behavioral currency union model}

The following derivation is based on the rational expectations open economy model in Galí and Monacelli (2005) and on the behavioral closed economy model in Kurz et al. (2013); see also Galí and Monacelli (2008), and Hommes et al. (2019).

\section{A1. Households}

Consider a generic country $i$ part of the currency union. Household $j$ in country $i$ chooses consumption $C_{j, t}^{i}$, labor $N_{j, t}^{i}$ and bond holdings $B_{j, t}^{i}$ to maximise

$$
E_{j, t}^{i} \sum_{\tau=0}^{\infty} \beta^{\tau}\left(\frac{\left(C_{j, t+\tau}^{i}\right)^{1-\sigma}}{1-\sigma}-\frac{\left(N_{j, t+\tau}^{i}\right)^{1+\zeta}}{1+\zeta}\right) .
$$

The variable $C_{j, t}^{i}$ is a composite consumption index of household $j$ in country $i$ defined by

$$
C_{j, t}^{i}=\frac{\left(C_{j, i, t}^{i}\right)^{1-\alpha}\left(C_{j, F, t}^{i}\right)^{\alpha}}{(1-\alpha)^{1-\alpha} \alpha^{\alpha}} .
$$

Variable $C_{j, i, t}^{i}$ in Eq. (A.2) denotes consumption of household $j$, living in country $i$ (superscript), of goods produced in country $i$ (subscript), given by the CES aggregator

$$
C_{j, i, t}^{i}=\left(\int_{0}^{1} C_{j, i, t}^{i}(z)^{\frac{\epsilon-1}{\epsilon}} d z\right)^{\frac{\epsilon}{\epsilon-1}},
$$

where $z \in[0,1]$ indexes the type of good, within the set produced in country $i$. Following Galí and Monacelli (2005), we assume that each country produces a continuum of differentiated goods, that each good is produced by a distinct firm, and that no good is produced in more than one country.

Variable $C_{j, F, t}^{i}$ in Eq. (A.2) is an index of consumer $j$ 's consumption of imported goods given by

$$
C_{j, F, t}^{i}=\exp \int_{0}^{1} c_{j, f, t}^{i} d f,
$$

where $c_{j, f, t}^{i}=\log C_{j, f, t}^{i}$ is the $\log$ of an index of the quantity of goods consumed by household $j$ in country $i$, and produced in country $f$. In what follows, lower case letters will denote logs of the respective variables.

The index $C_{j, f, t}^{i}$ is defined symmetrically to $C_{j, i, t}^{i}$, namely

$$
C_{j, f, t}^{i}=\left(\int_{0}^{1} C_{j, f, t}^{i}(z)^{\frac{\epsilon-1}{\epsilon}} d z\right)^{\frac{\epsilon}{\epsilon-1}} .
$$

Denoting the index of prices of domestically produced goods as $P_{t}^{i}=\left(\int_{0}^{1} P_{t}^{i}(z)^{1-\epsilon} d z\right)^{1 /(1-\epsilon)}$, and the index of prices of goods imported from country $f$ as $P_{t}^{f}=\left(\int_{0}^{1} P_{t}^{f}(z)^{1-\epsilon} d z\right)^{1 /(1-\epsilon)}$, the optimal allocation of expenditures on the goods produced in a certain country gives the following demand functions

$$
\begin{aligned}
& C_{j, i, t}^{i}(z)=\left(\frac{P_{t}^{i}(z)}{P_{t}^{i}}\right)^{-\epsilon} C_{j, i, t}^{i} \\
& C_{j, f, t}^{i}(z)=\left(\frac{P_{t}^{f}(z)}{P_{t}^{f}}\right)^{-\epsilon} C_{j, f, t}^{i} .
\end{aligned}
$$

Therefore we have that $\int_{0}^{1} P_{t}^{i}(z) C_{j, i, t}^{i}(z) d z=P_{t}^{i} C_{j, i, t}^{i}$ and $\int_{0}^{1} P_{t}^{f}(z) C_{j, f, t}^{i}(z) d z=P_{t}^{f} C_{j, f, t}^{i}$. Moreover, optimal allocation of expenditures on imported goods by country of origins yields

$$
P_{t}^{f} C_{j, f, t}^{i}=P_{t}^{*} C_{j, F, t}^{i}
$$


where $P_{t}^{*}=\exp \int_{0}^{1} p_{t}^{f} d f$ is the union-wide price index (as there is a continuum of countries, $P_{t}^{*}=P_{t}^{* i}$, that is the union-wide price index is identical to the price index "abroad", excluding country $i$ ). Finally, defining

$$
P_{c, t}^{i}=\left(P_{t}^{i}\right)^{1-\alpha}\left(P_{t}^{*}\right)^{\alpha}
$$

as the consumer price index (CPI) for country $i$, we can write the optimal allocation of expenditures between imported and domestically produced goods as

$$
\begin{aligned}
P_{t}^{i} C_{j, i, t}^{i} & =(1-\alpha) P_{c, t}^{i} C_{j, t}^{i} \\
P_{t}^{*} C_{j, F, t}^{i} & =\alpha P_{c, t}^{i} C_{j, t}^{i} .
\end{aligned}
$$

We can then write the households' budget constraint as

$$
P_{c, t}^{i} C_{j, t}^{i}+B_{j, t}^{i}=B_{j, t-1}^{i} R_{t-1}+W_{t}^{i} N_{j, t}^{i}-T_{j, t}^{i},
$$

where $R_{t}$ is the union-wide gross interest, $W_{t}^{i}$ is the gross wage, and $T_{j, t}^{i}$ are lump sum transfers including profits from firms. The first order conditions for household's $j$ optimisation problem are given by

$$
\begin{aligned}
& \left(C_{j, t}^{i}\right)^{-\sigma}=\beta R_{t} E_{j, t}^{i}\left(\left(C_{j, t+1}^{i}\right)^{-\sigma} \frac{P_{c, t}^{i}}{P_{c, t+1}^{i}}\right) \\
& \left(C_{j, t}^{i}\right)^{-\sigma} \frac{W_{t}^{i}}{P_{c, t}^{i}}=\left(N_{j, t}^{i}\right)^{\zeta} .
\end{aligned}
$$

As standard, we require that agents' subjective transversality condition is satisfied, $\lim _{\tau \rightarrow \infty} E_{j, t}^{i} \beta^{t+\tau}\left(C_{j, t+\tau}^{i}\right)^{-\sigma} \frac{B_{j, t+\tau}^{i}}{P_{c, t+\tau}^{i}} \leq 0$ (see Branch and McGough, 2009).

\section{A2. Domestic and CPI Inflation} as

Define the bilateral terms of trade between countries $i$ and $f$ as $S_{f, t}^{i} \equiv P_{t}^{f} / P_{t}^{i}$. The effective terms of trade can then be written

$$
S_{t}^{i}=P_{t}^{*} / P_{t}^{i}=\exp \int_{0}^{1}\left(p_{t}^{f}-p_{t}^{i}\right) d f=\exp \int_{0}^{1} s_{f, t}^{i} d f .
$$

Therefore taking logs we have $s_{t}^{i}=\int_{0}^{1} s_{f, t}^{i} d f$.

Using Eq. (A.3) we can derive the following relationship between CPI and domestic price levels

$$
P_{c, t}^{i}=P_{t}^{i}\left(S_{t}^{i}\right)^{\alpha},
$$

which can be rewritten in logs as

$$
p_{c, t}^{i}=p_{t}^{i}+\alpha s_{t}^{i} .
$$

From the previous equation it follows that the relationship between domestic inflation, defined as $\pi_{t}^{i}=p_{t}^{i}-p_{t-1}^{i}$, and CPI inflation, defined as $\pi_{c, t}^{i}=p_{c, t}^{i}-p_{c, t-1}^{i}$, is given by

$$
\pi_{c, t}^{i}=\pi_{t}^{i}+\alpha \Delta s_{t}^{i}
$$

\section{A3. Firms}

Each firm in country $i$ produces a differentiated good, indexed by $z$, with a linear technology

$$
Y_{t}^{i}(z)=A_{t}^{i} N_{t}^{i}(z)
$$

where $A_{t}^{i}$ is a country-specific productivity process. Real marginal costs are therefore common across firms in country $i$ and given by

$$
m c_{t}^{i}=w_{t}^{i}-p_{t}^{i}-a_{t}^{i}
$$

Moreover, denoting the aggregate output index for country $i$ as $Y_{t}^{i}=\left(\int_{0}^{1} Y_{t}^{i}(z)^{\frac{\epsilon-1}{\epsilon}} d z\right)^{\frac{\epsilon}{\epsilon-1}}$, we can derive the following loglinearized relationship between aggregate output and aggregate employment in country $i$ (see Galí and Monacelli, 2005 for a detailed derivation).

$$
y_{t}^{i}=a_{t}^{i}+n_{t}^{i} .
$$

We assume a staggered price setting à la Calvo, where only a fraction $1-\omega$ of prices are readjusted in every period. Moreover, we consider a scenario in which households have equal ownership shares in all firms (so that income effects of 
random price adjustments are removed), though each household manages only one firm (i.e., makes price decisions for only one firm).

Let $Q_{t}^{i, o p t}(z)=P_{t}^{i, o p t}(z) / P_{t}^{i}$ denote the optimal price set by firm producing good $z$ relative to the aggregate price level. The optimal price-setting strategy for a firm resetting its price in period $t$ log-linearized around steady state is given by

$$
\hat{q}_{t}^{i, o p t}(z)=(1-\omega \beta) E_{z, t}^{i} \sum_{\tau=0}^{\infty}(\omega \beta)^{\tau}\left(\widehat{m c}_{t+\tau}^{i}+\pi_{t+\tau}^{i}\right),
$$

where $\hat{x}_{t}=x_{t}-x$ denotes $\log$ deviations from steady state for a generic variable $X_{t}$.

A4. Aggregate demand and New Keynesian Phillips curve

Aggregating individual demands across households, the market clearing for good $z$ produced in country $i$ implies that

$$
\begin{aligned}
Y_{t}^{i}(z) & =\int_{0}^{1} C_{j, i, t}^{i}(z) d j+\int_{0}^{1} \int_{0}^{1} C_{j, i, t}^{f}(z) d j d f \\
& =\left(\frac{P_{t}^{i}(z)}{P_{t}^{i}}\right)^{-\epsilon}\left(\int_{0}^{1} C_{j, i, t}^{i} d j+\int_{0}^{1} \int_{0}^{1} C_{j, i, t}^{f} d j d f\right) \\
& =\left(\frac{P_{t}^{i}(z)}{P_{t}^{i}}\right)^{-\epsilon}\left(C_{i, t}^{i}+\int_{0}^{1} C_{i, t}^{f} d f\right) .
\end{aligned}
$$

Aggregating the equations in (A.4) across households yields

$$
\begin{aligned}
P_{t}^{i} C_{i, t}^{i} & =(1-\alpha) P_{c, t}^{i} C_{t}^{i} \\
P_{t}^{*} C_{F, t}^{i} & =\alpha P_{c, t}^{i} C_{t}^{i} .
\end{aligned}
$$

Substituting (A.14) in (A.13) gives

$$
\begin{aligned}
Y_{t}^{i}(z) & =\left(\frac{P_{t}^{i}(z)}{P_{t}^{i}}\right)^{-\epsilon}\left((1-\alpha) \frac{P_{c, t}^{i}}{P_{t}^{i}} C_{t}^{i}+\alpha \int_{0}^{1} \frac{P_{c, t}^{f}}{P_{t}^{i}} C_{t}^{f} d f\right) \\
& =\left(\frac{P_{t}^{i}(z)}{P_{t}^{i}}\right)^{-\epsilon}\left((1-\alpha)\left(S_{t}^{i}\right)^{\alpha} C_{t}^{i}+\alpha\left(S_{t}^{i}\right)^{\alpha} \int_{0}^{1} \frac{P_{c, t}^{f}}{P_{c, t}^{i}} C_{t}^{f} d f\right) .
\end{aligned}
$$

Combining individual first order conditions for households in country $i$ and $f$ yields

$$
\beta E_{j, t}^{i}\left(\left(\frac{C_{j, t+1}^{i}}{C_{j, t}^{i}}\right)^{-\sigma}\left(\frac{P_{c, t}^{i}}{P_{c, t+1}^{i}}\right)\right)=\beta E_{j, t}^{f}\left(\left(\frac{C_{j, t+1}^{f}}{C_{j, t}^{f}}\right)^{-\sigma}\left(\frac{P_{c, t}^{f}}{P_{c, t+1}^{f}}\right)\right) .
$$

We assume

$$
\vartheta \equiv \frac{\int_{0}^{1} E_{j, t}^{i}\left(C_{j, t+1}^{i}\left(P_{c, t+1}^{i}\right)^{1 / \sigma}\right) d j}{\int_{0}^{1} E_{j, t}^{f}\left(C_{j, t+1}^{f}\left(P_{c, t+1}^{f}\right)^{1 / \sigma}\right) d j}=1 .
$$

This assumption is satisfied in the rational benchmark model (Galí and Monacelli, 2005). It simplifies the derivation and allows a focus on the expectations of output gap and inflation alone, without the need to introduce further different types of expectations (adding further specifications of behavioral expectations and thereby allowing $\vartheta$ to vary may be interesting for future research).

Integrating across households in both countries yields

$$
C_{t}^{i}=\left(\frac{P_{c, t}^{f}}{P_{c, t}^{i}}\right)^{\frac{1}{\sigma}} C_{t}^{f}
$$

Substituting (A.18) in (A.15) we obtain

$$
\begin{aligned}
Y_{t}^{i}(z) & =\left(\frac{P_{t}^{i}(z)}{P_{t}^{i}}\right)^{-\epsilon}\left((1-\alpha)\left(S_{t}^{i}\right)^{\alpha} C_{t}^{i}+\alpha\left(S_{t}^{i}\right)^{\alpha} C_{t}^{i} \int_{0}^{1}\left(\frac{P_{c, t}^{f}}{P_{c, t}^{i}}\right)^{\frac{\sigma-1}{\sigma}} d f\right) \\
& =\left(\frac{P_{t}^{i}(z)}{P_{t}^{i}}\right)^{-\epsilon}\left((1-\alpha)\left(S_{t}^{i}\right)^{\alpha} C_{t}^{i}+\alpha\left(S_{t}^{i}\right)^{\alpha} C_{t}^{i} \int_{0}^{1}\left(S_{f, t}^{i}\right)^{\frac{(1-\alpha)(\sigma-1)}{\sigma}} d f\right) .
\end{aligned}
$$


Plugging (A.19) into the definition of of country $i$ 's aggregate output $Y_{t}^{i}=\left(\int_{0}^{1}\left(Y_{t}^{i}(z)\right)^{\frac{\epsilon-1}{\epsilon}} d z\right)^{\frac{\epsilon}{\epsilon-1}}$ we obtain the aggregate goods market clearing condition for country $i$

$$
Y_{t}^{i}=C_{t}^{i}\left((1-\alpha)\left(S_{t}^{i}\right)^{\alpha}+\alpha\left(S_{t}^{i}\right)^{\alpha} \int_{0}^{1}\left(S_{f, t}^{i}\right)^{\frac{(1-\alpha)(\sigma-1)}{\sigma}} d f\right)
$$

which can be log-linearized around a symmetric steady state (using the fact that in a symmetric steady state $S^{i}=1$ and therefore $s^{i}=0$ ) as

$$
\hat{y}_{t}^{i}=\hat{c}_{t}^{i}+\frac{\alpha \theta}{\sigma} s_{t}^{i}
$$

where $\theta=\sigma+(1-\alpha)(\sigma-1)$. Log-linearizing the Euler Eq. (A.6) yields

$$
\hat{c}_{j, t}^{i}=E_{j, t}^{i} \hat{c}_{j, t+1}^{i}-\sigma^{-1}\left(r_{t}-E_{j, t}^{i} \pi_{c, t+1}^{i}-\rho\right),
$$

where $\rho=-\log \beta$, which can be rewritten as

$$
\hat{c}_{j, t}^{i}=E_{j, t}^{i} \hat{c}_{t+1}^{i}+\left(E_{j, t}^{i} \hat{c}_{j, t+1}^{i}-E_{j, t}^{i} \hat{c}_{t+1}^{i}\right)-\sigma^{-1}\left(r_{t}-E_{j, t}^{i} \pi_{c, t+1}^{i}-\rho\right) .
$$

Aggregating the previous equation across households we get

$$
\hat{c}_{t}^{i}=\bar{E}_{t}^{i} \hat{c}_{t+1}^{i}-\sigma^{-1}\left(r_{t}-\bar{E}_{t}^{i} \pi_{c, t+1}^{i}-\rho\right)+\Phi_{t}^{i}(\hat{c}),
$$

where $\bar{E}_{t}^{i}$ is the aggregate expectation operator defined as $\bar{E}_{t}^{i}\left(x_{t+1}\right)=\int_{0}^{1} E_{j, t}^{i} x_{t+1} d j$ for a generic variable $x$ and the term $\Phi_{t}^{i}(\hat{c})=\int_{0}^{1}\left(E_{j, t}^{i} \hat{c}_{j, t+1}^{i}-E_{j, t}^{i} \hat{c}_{t+1}^{i}\right) d j$ denotes the difference between the average expectation of individual consumption and average consumption.

Substituting (A.21) in (A.23), we obtain

$$
\hat{y}_{t}^{i}=\bar{E}_{t}^{i} \hat{y}_{t+1}^{i}-\sigma^{-1}\left(r_{t}-\bar{E}_{t}^{i} \pi_{c, t+1}^{i}-\rho\right)-\frac{\alpha \theta}{\sigma} \bar{E}_{t}^{i} \Delta s_{t+1}^{i}+\Phi_{t}^{i}(\hat{c}),
$$

which can be rewritten using (A.9) as

$$
\hat{y}_{t}^{i}=\bar{E}_{t}^{i} \hat{y}_{t+1}^{i}-\sigma^{-1}\left(r_{t}-\bar{E}_{t}^{i} \pi_{t+1}^{i}-\rho\right)+\frac{\alpha(1-\theta)}{\sigma} \bar{E}_{t}^{i} \Delta s_{t+1}^{i}+\Phi_{t}^{i}(\hat{c}) .
$$

We now turn to the supply side of the economy. Since each firm produces a single good $z$ and is managed by a single household $j$ (with subjective expectations $j$ ), we can, without loss of generality, use a single index, say $j$, to denote the produced good and the subjective expectations of the firm. We can therefore write the individual pricing rule in (A.12) as

$$
\hat{q}_{t}^{i, o p t}(j)=(1-\omega \beta) \widehat{m c}_{t}^{i}+\omega \beta E_{j, t}^{i}\left(\hat{q}_{t}^{i, o p t}(j)+\pi_{t+1}^{i}\right) \text {. }
$$

Given the Calvo pricing scheme, in each period only a set of firms $F_{t} \in[0,1]$ of measure $1-\omega$ adjust prices, while a set $F_{t}^{c} \in[0,1]$ of measure $\omega$ do not adjust. Assuming that the sample of firms allowed to adjust prices in each period is selected independently across agents so that the distribution of firms in terms of beliefs is the same whether we consider firms that adjust prices or firms that do not adjust prices, we can write using the aggregate price definition

$$
\left(P_{t}^{i}\right)^{1-\epsilon}=\int_{F_{t}}\left(P_{t}^{i, o p t}(j)\right)^{1-\epsilon} d j+\int_{F_{t}^{c}}\left(P_{t-1}^{i}(j)\right)^{1-\epsilon} d j
$$

which can be rewritten as

$$
1=(1-\omega) \int_{0}^{1}\left(Q_{t}^{i, o p t}(j)\right)^{1-\epsilon} d j+\omega\left(P_{t}^{i} / P_{t-1}^{i}\right)^{\epsilon-1}
$$

Log-linearizing the relation above we get

$$
\pi_{t}^{i}=\frac{1-\omega}{\omega} \int_{0}^{1} \hat{q}_{t}^{i, o p t}(j) d j .
$$

Denoting $\hat{q}_{t}^{i}=\int \hat{q}_{t}^{i, o p t}(j) d j$ and integrating Eq. (A.25) on both sides we get

$$
\hat{q}_{t}^{i}=(1-\omega \beta) \widehat{m c}_{t}^{i}+\omega \beta \int_{0}^{1} E_{j, t}^{i}\left(\hat{q}_{t+1}^{i, o p t}(j)+\pi_{t+1}^{i}\right) d j
$$

which can be rewritten as

$$
\hat{q}_{t}^{i}=(1-\omega \beta) \widehat{m c}_{t}^{i}+\omega \beta \int_{0}^{1} E_{j, t}^{i}\left(\hat{q}_{t+1}^{i, o p t}(j)+\hat{q}_{t+1}^{i}-\hat{q}_{t+1}^{i}+\pi_{t+1}^{i}\right) d j .
$$

Recalling from Eq. (A.26) that $\hat{q}_{t}^{i}=\omega /(1-\omega) \pi_{t}^{i}$ and substituting in the equation above we get

$$
\pi_{t}^{i}=\frac{(1-\omega)(1-\omega \beta)}{\omega} \widehat{m c}_{t}^{i}+\beta \bar{E}_{t}^{i} \pi_{t+1}^{i}+\Phi_{t}^{i}(\hat{q})
$$


where again $\bar{E}_{t}^{i}$ is the aggregate expectation operator and $\Phi_{t}^{i}(\hat{q})=\beta(1-\omega) \int_{0}^{1}\left(E_{j, t}^{i} \hat{q}_{t+1}^{i, o p t}(j)-E_{j, t}^{i} \hat{q}_{t+1}^{i}\right) d j$ denotes the difference between the average expectation of individual price and average price.

Log-linearizing Eq. (A.7), and using (A.10) and (A.11) combined with market clearing result (A.21), we can express real marginal costs as a function of output, productivity and the effective terms of trade

$$
\widehat{m c}_{t}^{i}=(\sigma+\zeta) \hat{y}_{t}^{i}-(1+\zeta) a_{t}^{i}+\alpha(1-\theta) s_{t}^{i} .
$$

Recall from (A.18) that

$$
C_{t}^{i}=\left(S_{f, t}^{i}\right)^{\frac{1-\alpha}{\sigma}} C_{t}^{f} .
$$

Log-linearizing the above expression gives

$$
\hat{c}_{t}^{i}=\hat{c}_{t}^{f}+\frac{1-\alpha}{\sigma} s_{f, t}^{i},
$$

and integrating over $f$ yields

$$
\hat{c}_{t}^{i}=\hat{c}_{t}^{c u}+\frac{1-\alpha}{\sigma} s_{t}^{i},
$$

where $\hat{c}_{t}^{c u}$ is consumption at the currency union level. Integrating Eq. (A.21) over $i$ we get $\hat{y}_{t}^{c u}=\hat{c}_{t}^{c u}$ since $\int_{0}^{1} s_{t}^{i} d i=0$. Therefore, substituting (A.29) in (A.21) we get

$$
\hat{y}_{t}^{i}=\hat{y}_{t}^{c u}+\frac{1}{\sigma_{\alpha}} s_{t}^{i},
$$

where $\sigma_{\alpha}=\frac{\sigma}{1+\alpha(\theta-1)}$.

Using (A.30) in (A.28) to substitute for $s_{t}^{i}$ we get

$$
\widehat{m c}_{t}^{i}=(\sigma+\zeta) \hat{y}_{t}^{i}-(1+\zeta) a_{t}^{i}+\alpha(1-\theta)\left(\hat{y}_{t}^{i}-\hat{y}_{t}^{c u}\right) \sigma_{\alpha} .
$$

Eq. (A.31) implies a natural level of output under flexible prices given by

$$
\hat{y}_{t}^{i, n}=\frac{(1+\zeta)}{\sigma+\zeta+\alpha(1-\theta) \sigma_{\alpha}} a_{t}^{i}+\frac{\alpha(1-\theta) \sigma_{\alpha}}{\sigma+\zeta+\alpha(1-\theta) \sigma_{\alpha}} y_{t}^{c u} .
$$

Defining the output gap as $\tilde{y}_{t}^{i}=\hat{y}_{t}^{i}-\hat{y}_{t}^{i, n}$ we can write Eq. (A.31) as

$$
\widehat{m c}_{t}^{i}=\left(\sigma_{\alpha}+\zeta\right) \tilde{y}_{t}^{i} .
$$

Therefore, substituting (A.33) in (A.27) we get

$$
\pi_{t}^{i}=k \tilde{y}_{t}^{i}+\beta \bar{E}_{t}^{i} \pi_{t+1}^{i}+\Phi_{t}^{i}(\hat{q}),
$$

where $k=\frac{(1-\omega)(1-\omega \beta)\left(\sigma_{\alpha}+\zeta\right)}{\omega}$.

Rewriting Eq. (A.24) in terms of the output gap yields

$$
\tilde{y}_{t}^{i}=\bar{E}_{t}^{i} \tilde{y}_{t+1}^{i}-\sigma^{-1}\left(r_{t}-\bar{E}_{t}^{i} \pi_{t+1}^{i}-\rho\right)+\gamma \bar{E}_{t}^{i} \Delta s_{t+1}^{i}+\Phi_{t}^{i}(\hat{c})+v_{t}^{i},
$$

where $\gamma=\frac{\alpha(1-\theta)}{\sigma}$ and $v_{t}^{i}=\frac{(1+\zeta)}{\sigma+\zeta+\alpha(1-\theta) \sigma_{\alpha}} \bar{E}_{t}^{i}\left(a_{t+1}^{i}-a_{t}^{i}\right)+\frac{\alpha(1-\theta) \sigma_{\alpha}}{\sigma+\zeta+\alpha(1-\theta) \sigma_{\alpha}} \bar{E}_{t}^{i}\left(y_{t+1}^{c u}-y_{t}^{c u}\right)$. We assume that expectations of changes in productivity and currency union level output gap are white noise.

Furthermore, as Hommes et al. (2019), we assume that agents' expectations of future individual consumption and price will coincide with their expectations about future average consumption and price, so that the terms $\Phi_{t}(\hat{c})$ and $\Phi_{t}(\hat{q})$ are equal to zero. Note that the terms $\Phi_{t}(\hat{c})$ and $\Phi_{t}(\hat{q})$ drop out under a variety of different assumptions on agents' beliefs. For example under the benchmark of rational beliefs, $\Phi_{t}(\hat{c})$ and $\Phi_{t}(\hat{q})$ are equal to zero. In a behavioral model, Hommes and Lustenhouwer (2019) argue that, when agents are switching among different forecasting rules and know that the probability of adopting a certain rule is the same across individuals, expectations about future individual and aggregate consumption/price coincide. Also, if people have the naive belief that all other people will consume as much as they will consume themselves and that all others will set the same prices as the will, the terms equal zero. Even more, if people belief that other people will on average consume as much as they will consume themselves and that all others will on average set the same prices as the will, the terms equal zero. The terms even do not have to equal zero precisely: as long as these terms are not systematically biased, that is, as long as they are random deviations from one of the conditions described above, they can be combined with the shocks that are present anyways.

We can therefore rewrite the aggregate demand and supply equations as

$$
\begin{aligned}
& \tilde{y}_{t}^{i}=\bar{E}_{t}^{i} \tilde{y}_{t+1}^{i}-\sigma^{-1}\left(r_{t}-\bar{E}_{t}^{i} \pi_{t+1}^{i}-\rho\right)+\gamma \bar{E}_{t}^{i} \Delta s_{t+1}^{i}+v_{t}^{i} \\
& \pi_{t}^{i}=k \tilde{y}_{t}^{i}+\beta \bar{E}_{t}^{i} \pi_{t+1}^{i}+\xi_{t}^{i},
\end{aligned}
$$

where $\xi_{t}^{i}$ is a cost-push shock at the country level. 


\section{Supplementary material}

Supplementary material associated with this article can be found, in the online version, at doi:10.1016/j.jedc.2020.103850.

\section{References}

Anufriev, M., Hommes, C.H., 2012. Evolutionary selection of individual expectations and aggregate outcomes. Am. Econ. J. Microecon. 4, 35-64.

Assenza, T., Heemeijer, P., Hommes, C., Massaro, D., 2019. Managing self-organization of expectations through monetary policy: a macro experiment. J. Monet. Econ. https://www.sciencedirect.com/science/article/pii/S0304393219302181. Forthcoming

Blanchflower, D.G., MacCoille, C., 2009. The formation of inflation expectations: an empirical analysis for the UK. NBER Working Paper No. 15388.

Bonam, D., Goy, G., 2019. Home biased expectations and macroeconomic imbalances in a monetary union. J. Econ. Dyn. Control 103, 25-42.

Branch, W., 2004. The theory of rationally heterogeneous expectations: evidence from survey data on inflation expectations. Econ. J. 114 (497), 592-621.

Branch, W., McGough, B., 2009. A New Keynesian model with heterogeneous expectations. J. Econ. Dyn. Control 33, $1036-1051$.

Branch, W., McGough, B., 2010. Dynamic predictors selection in a New Keynesian model with heterogeneous expectations. J. Econ. Dyn. Control 34 (8), $1492-1508$

Branch, W.A., Evans, G.W., 2011. Monetary policy and heterogeneous expectations. Econ. Theory 47 (2-3), 365-393.

Brock, W.A., Hommes, C.H., 1997. A rational route to randomness. Econometrica 65 (5), 1059-1095.

Brock, W.A., Hommes, C.H., 1998. Heterogeneous beliefs and routes to chaos in a simple asset pricing model. J. Econ. Dyn. Control 22, 1235-1274.

Carroll, C., 2003. Macroeconomic expectations of households and professional forecasters. Q. J. Econ. 118, 269-298.

Comunale, M., 2015. Financial cycle measures for 41 countries: a new database. Bank of Lithuania Occasional Paper No 9 / 2015

Cornand, C., Hubert, P., 2020. On the external validity of experimental inflation forecasts: a comparison with five categories of field expectations. J. Econ. Dyn. Control 110 https://www.sciencedirect.com/science/article/pii/S0165188919301459. Forthcoming

Cornea, A., Hommes, C., Massaro, D., 2019. Behavioral heterogeneity in U.S. inflation dynamics. J. Business and Economic Statistics 37, 288-300.

De Grauwe, P., 2010. The scientific foundation of dynamic stochastic general equilibrium (DSGE) models. Public Choice 144 (3-4), 413-443.

De Grauwe, P., 2011. Animal spirits and monetary policy. Economic theory 47 (2-3), 423-457.

De Grauwe, P., 2012a. Booms and busts in economic activity: A behavioral explanation. J. Economic Behavior \& Organization 83 (3), 484-501.

De Grauwe, P., 2012b. Lectures on behavioral macroeconomics. Princeton University Press, New Jersey.

De Grauwe, P., Ji, Y., 2017. The international synchronisation of business cycles: the role of animal spirits. Open Economies Review 28 (3), 383-412.

Dees, S., Pesaran, M. H., Smith, L. V., Smith, R., 2010. Supply, demand and monetary policy shocks in a multi-country New Keynesian model. ECB Working paper No 1239.

Diks, C., van der Weide, R., 2005. Herding, a-synchronous updating and heterogeneity in memory in a CBS. J. Econ. Dyn. Control 29, 741-763.

Evans, G., Honkapohja, S., 2006. Monetary policy, expectations and commitment. Scand. J. Econ. 108, 15-38.

Evans, G.W., Honkapohja, S., 2001. Learning and Expectations in Macroeconomics. Princeton University Press.

Galí, J., Monacelli, T., 2005. Monetary policy and exchange rate volatility in a small open economy. Rev. Econ. Stud. 72 (3), $707-734$.

Galí, J., Monacelli, T., 2008. Optimal monetary and fiscal policy in a currency union. J. Int. Econ. 76 (1), 116-132.

Gigerenzer, G., Selten, R., 2002. Bounded Rationality: The Adaptive Toolbox. MIT Press.

Gigerenzer, G., Todd, P.M., 1999. Simple Heuristics That Make Us Smart. Oxford University Press, USA.

Grether, D., Plott, C., 1979. Economic theory of choice and the preference reversal phenomenon. Am. Econ. Rev. 69 (4), $623-638$

Hommes, C., Lustenhouwer, J., 2019. Inflation targeting and liquidity traps under endogenous credibility. J. Monet. Econ. 107, 48-62.

Hommes, C.H., 2011. The heterogeneous expectations hypothesis: Some evidence from the lab. J. Econ. Dyn. Control 35, 1-24.

Hommes, C.H., Huang, H., Wang, D., 2005a. A robust rational route to randomness in a simple asset pricing model. J. Econ. Dyn. Control 29, 1043-1072.

Hommes, C.H., Massaro, D., Weber, M., 2019. Monetary policy under behavioral expectations: Theory and experiment. Eur. Econ. Rev. 118, 193-212.

Hommes, C.H., Sonnemans, J., Tuinstra, J., van de Velden, H., 2005b. Coordination of expectations in asset pricing experiments. Rev. Financ. Stud. 18 (3), 955-980.

Hommes, C.H., Sonnemans, J., Tuinstra, J., van de Velden, H., 2008. Expectations and bubbles in asset pricing experiments. J. Econ. Behav. Organ. 67 (1), $116-133$.

Kobielarz, M. L., 2017. Unstable monetary unions - the role of expectations and past experience. Tilburg University Working Paper.

Kurz, M., Piccillo, G., Wu, H., 2013. Modeling diverse expectations in an aggregated New Keynesian model. J. Econ. Dyn. Control 37, $1403-1433$.

Malmendier, U., Nagel, S., 2016. Learning from inflation experiences. Q. J. Econ. 131 (1), 53-87.

Massaro, D., 2013. Heterogeneous expectations in monetary dsge models. J. Econ. Dyn. Control 37 (3), 680-692.

Pfajfar, D., Santoro, E., 2010. Heterogeneity, learning and inflation stickiness in inflation expectations. J. Econ. Behav. Organ. 75 (3), $426-444$.

Pfajfar, D., Zakelj, B., 2014. Experimental evidence on inflation expectations formation. J. Econ. Dyn. Control 44, 147-168.

Richman, B.D., 2005. Behavioral economics and health policy: Understanding medicaid's failure. Cornell Law Rev. 90 (3), $705-768$.

Thaler, R.H., Benartzi, S., 2004. Save more tomorrow ${ }^{\mathrm{TM}}$ : using behavioral economics to increase employee saving. J. Political Econ. 112 (S1), S164-S187.

Torój, A., 2010. Rationality of expectations: another OCA criterion? A DSGE analysis. Central Eur. J. Econ. Modell. Econ. 3 (2), $205-252$.

Tversky, A., Kahneman, D., 1974. Judgement under uncertainty: heuristics and biases. Science 185, 1124-1130.

Weber, M., Duffy, J., Schram, A., 2018. An experimental study of bond market pricing. J. Financ. 73 (4), $1857-1892$.

Weber, M., Schram, A., 2017. The non-equivalence of labour market taxes: A real-effort experiment. Econ. J. 127 (604), $2187-2215$.

Woodford, M., 1999. Optimal monetary policy inertia. NBER Working Paper No 7261. 


\title{
Online Appendix to "The Behavioral \\ Economics of Currency Unions: Economic Integration and Monetary Policy"
}

\author{
Akvile Bertasiute, Domenico Massaro, Matthias Weber
}

This online appendix contains material in addition to the main text and to the printed appendix, Appendix A.

\section{B Matrix Forms of the Macroeconomic Equations and Additional Derivations and Results}

\section{B.1 Matrix Form}

The currency union model consisting of Equations (1)-(2) for each country $i, i=1, \ldots, N$ and Equation (3) can be written in matrix form as

$$
x_{t}=M x_{t+1}^{e}+D+R \varepsilon_{t}
$$

with the following notation:

$$
x_{t}:=\left[\begin{array}{c}
y_{t}^{1} \\
\vdots \\
y_{t}^{N} \\
\pi_{t}^{1} \\
\vdots \\
\pi_{t}^{N}
\end{array}\right], x_{t+1}^{e}:=\left[\begin{array}{c}
\bar{E}_{t}^{1} y_{t+1}^{1} \\
\vdots \\
\bar{E}_{t}^{N} y_{t+1}^{N} \\
\bar{E}_{t}^{1} \pi_{t+1}^{1} \\
\vdots \\
\bar{E}_{t}^{N} \pi_{t+1}^{N}
\end{array}\right], \varepsilon_{t}:=\left[\begin{array}{c}
v_{t}^{1} \\
\vdots \\
v_{t}^{N} \\
\xi_{t}^{1} \\
\vdots \\
\xi_{t}^{N}
\end{array}\right]
$$




$$
\begin{aligned}
& \Omega:=\left[\begin{array}{cccccc}
1+\frac{\Phi_{y} w(1)}{\sigma^{1} \sum_{k=1}^{N} w(k)} & \cdots & \frac{\Phi_{y} w(N)}{\sigma^{1} \sum_{k=1}^{N} w(k)} & \frac{\Phi_{\pi} w(1)}{\sigma^{1} \sum_{k=1}^{N} w(k)} & \cdots & \frac{\Phi_{\pi} w(N)}{\sigma^{1} \sum_{k=1}^{N} w(k)} \\
\vdots & \ddots & \vdots & \vdots & & \vdots \\
\frac{\Phi_{y} w(1)}{\sigma^{N} \sum_{k=1}^{N} w(k)} & \cdots & 1+\frac{\Phi_{y} w(N)}{\sigma^{N} \sum_{k=1}^{N} w(k)} & \frac{\Phi_{\pi} w(1)}{\sigma^{N} \sum_{k=1}^{N} w(k)} & \cdots & \frac{\Phi_{\pi} w(N)}{\sigma^{N} \sum_{k=1}^{N} w(k)} \\
-\kappa^{1} & \cdots & 0 & 1 & \cdots & 0 \\
\vdots & & \vdots & \vdots & \ddots & \vdots \\
0 & \cdots & -\kappa^{N} & 0 & \cdots & 1
\end{array}\right], \\
& M:=\Omega^{-1}\left[\begin{array}{cccccc}
1 & \cdots & 0 & \frac{1}{\sigma^{1}}-\gamma^{1} & \cdots & \frac{\gamma^{1} w(N)}{\sum_{k=1}^{N, k \neq 1} w(k)} \\
\vdots & \ddots & \vdots & \vdots & \ddots & \vdots \\
0 & \cdots & 1 & \frac{\gamma^{N} w(1)}{\sum_{k=1}^{N, k \neq N} w(k)} & \cdots & \frac{1}{\sigma^{N}}-\gamma^{N} \\
0 & \cdots & 0 & \beta^{1} & \cdots & 0 \\
\vdots & \ddots & \vdots & \vdots & \ddots & \vdots \\
0 & \cdots & 0 & 0 & \cdots & \beta^{N}
\end{array}\right] \\
& D:=\Omega^{-1}\left[\begin{array}{cccccc}
\frac{\Phi_{y} w(1)}{\sigma^{1} \sum_{k=1}^{N} w(k)} & \cdots & \frac{\Phi_{y} w(N)}{\sigma^{1} \sum_{k=1}^{N} w(k)} & -\frac{1-\Phi_{\pi}}{\sigma^{1}} & \cdots & 0 \\
\vdots & & \vdots & \vdots & \ddots & \vdots \\
\frac{\Phi_{y} w(1)}{\sigma^{N} \sum_{k=1}^{N} w(k)} & \cdots & \frac{\Phi_{y} w(N)}{\sigma^{N} \sum_{k=1}^{N} w(k)} & 0 & \cdots & -\frac{1-\Phi_{\pi}}{\sigma^{N}} \\
0 & \cdots & 0 & 0 & \cdots & 0 \\
\vdots & & \vdots & \vdots & \ddots & \vdots \\
0 & \cdots & 0 & 0 & \cdots & 0
\end{array}\right]\left[\begin{array}{c}
\bar{y}^{1} \\
\vdots \\
\bar{y}^{N} \\
\bar{\pi} \\
\vdots \\
\bar{\pi}
\end{array}\right], \\
& R:=\Omega^{-1}\left[\begin{array}{cccccc}
1 & \cdots & 0 & 0 & 0 & \\
\vdots & \ddots & \vdots & \vdots & & \vdots \\
0 & \cdots & 1 & 0 & \cdots & 0 \\
0 & \cdots & 0 & 1 & \cdots & 0 \\
\vdots & \ddots & \vdots & \vdots & \ddots & \vdots \\
0 & \cdots & 0 & 0 & \cdots & 1
\end{array}\right]
\end{aligned}
$$

This matrix notation describes the model economy correctly when the zero lower bound is not binding. When it is binding a similar form can be derived easily. 


\section{B.2 Determinacy and Mathematical Stability of Alternative Models of Expectation Formation}

Start from the deterministic skeleton of the currency union model in matrix form derived in Section B.1

$$
x_{t}=M x_{t+1}^{e}
$$

where $x_{t}=\left(y_{t}^{1}, \ldots, y_{t}^{N}, \pi_{t}^{1}, \ldots, \pi_{t}^{N}\right)^{\prime}$ and $x_{t+1}^{e}=\left(\bar{E}_{t}^{1} y_{t+1}^{1}, \ldots, \bar{E}_{t}^{N} y_{t+1}^{N}, \bar{E}_{t}^{1} \pi_{t+1}^{1}, \ldots, \bar{E}_{t}^{N} \pi_{t+1}^{N}\right)^{\prime}$. Matrix $M$ has $2 N$ eigenvalues. The absolute values of $2(N-1)$ eigenvalues depend on the economic integration parameter $\gamma$ and the number of countries in the currency union $N$ (as well as on the deep parameters $\beta, \kappa$ and $\sigma$ ), but do not depend on the monetary policy reaction coefficients $\Phi_{\pi}$ and $\Phi_{y}$. On the other hand, the absolute values of 2 eigenvalues depend on the monetary policy reaction coefficients $\Phi_{\pi}$ and $\Phi_{y}$ (as well as on the deep parameters $\beta, \kappa$ and $\sigma$ ), but do not depend on the economic integration parameter $\gamma$ and the number of countries in the currency union $N$.

This means that, when the currency union is unstable, e.g., due to a low level of economic integration, monetary policy alone cannot stabilize economic dynamics. Vice versa, when monetary policy does not react sufficiently to economic aggregates, higher economic integration cannot stabilize the currency union.

\section{B.2.1 Rational Expectations}

Determinacy in model (B.2) under rational expectations is obtained when all eigenvalues of matrix $M$ are within the unit circle. The largest of the eigenvalues of matrix $M$ that depend on the economic integration parameter $\gamma$ is given by

$$
\begin{aligned}
\lambda_{\max } & =\frac{(N-1)(1+\beta) \sigma+k((N-1)-N \gamma \sigma)}{2(N-1) \sigma}+ \\
& +\frac{\sqrt{(N-1)^{2}(-1+\beta)^{2} \sigma^{2}+k^{2}((N-1)-N \gamma \sigma)^{2}-2(N-1) k(1+\beta) \sigma(-(N-1)+N \gamma \sigma)}}{2(N-1) \sigma} .
\end{aligned}
$$

The modulus of $\lambda_{\max }$ is equal to one when $\gamma=\gamma^{*}=(N-1) /(N \sigma)$ (this can be easily verified by substitution). Figure B.1 displays the eigenvalues of matrix $M$ as functions of the economic integration parameter $\gamma$ for a currency union with $N=3$.

The eigenvalues that depend on monetary policy are the same eigenvalues of a closed economy, i.e., equations (1)-(3) with $\gamma=0$ and $N=1$. As it is well known, determinacy in a closed economy is obtained when monetary policy reaction coefficients satisfy the 


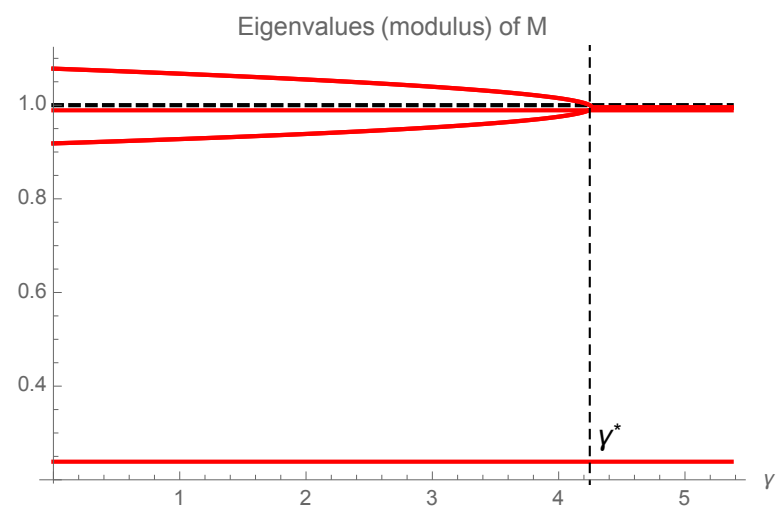

Figure B.1: Determinacy depending on $\gamma$

Notes: $\beta=0.99, \sigma=0.157, \kappa=0.001, \Phi_{\pi}=1.5, \Phi_{y}=0.5, N=3$. Parameter $\gamma$ is a convolution of the currency union's structural parameter $\sigma$ and the index of openness $\alpha \in[0,1]$, measuring the home bias in private consumption (see Appendix A for details). The range of $\gamma$ is thus obtained by letting $\alpha$ vary between 0 and 1.

following condition

$$
\kappa\left(\Phi_{\pi}-1\right)+(1-\beta) \Phi_{y}>0 .
$$

Therefore, provided that monetary satisfies condition (B.3), the model is determinate when $\gamma>\gamma^{*}$.

\section{B.2.2 Homogeneous Adaptive Rule}

Consider a model with homogeneous adaptive expectations

$$
x_{t+1}^{e}=\chi x_{t-1}+(1-\chi) x_{t}^{e},
$$

where $\chi=0.65$ in the main text. Rewrite the deterministic skeleton of the currency union model in matrix form as

$$
x_{t+1}^{e}=M^{-1} x_{t}
$$

and substitute Eq. (B.5) lagged one period in Eq. (B.4) to get

$$
x_{t+1}^{e}=\chi x_{t-1}+(1-\chi) M^{-1} x_{t-1} .
$$

Substituting Eq. (B.6) in Eq. (B.2) yields

$$
x_{t}=(\chi M+(1-\chi) I) x_{t-1} .
$$


Stability of the currency union model under homogeneous adaptive expectations depends on the eigenvalues of matrix $W=\chi M+(1-\chi) I$. In particular, it is straightforward to show that, when monetary policy satisfies condition (B.3), the currency union model under homogeneous adaptive expectations is stable when $\gamma>\gamma^{*}=(N-1) /(N \sigma)$, i.e., when the model is determinate under rational expectations. In fact, from the definition of eigenvalue it follows that

$$
M v=\lambda_{\max } v,
$$

where $v$ is the corresponding eigenvector. Pre-multiplying both sides of the equation above by scalar $\chi$ we get

$$
\chi M v=\chi \lambda_{\max } v
$$

Adding $(1-\chi) I v$ to both sides of the equation above we obtain

$$
\chi M v+(1-\chi) I v=\chi \lambda_{\max } v+(1-\chi) I v
$$

Rearranging terms in the equation above yields

$$
W v=\left(\chi \lambda_{\max }+(1-\chi)\right) v
$$

which implies that the largest eigenvalue of matrix $W$ is given by $\chi \lambda_{\max }+(1-\chi)$. It is thus straightforward to see that when the modulus of $\lambda_{\max }$ is equal to one, i.e., when $\gamma=\gamma^{*}$, so does the modulus of the largest eigenvalue of $W$. Figure B.1 displays the eigenvalues of matrix $W$ as functions of the economic integration parameter $\gamma$ for a currency union with $N=3$.

\section{B.2.3 Naive vs. Trend-following Rule}

Consider the following two forecasting heuristics:

$$
\begin{aligned}
& x_{1, t+1}^{e}=x_{t-1} \\
& x_{2, t+1}^{e}=x_{t-1}+\left(x_{t-1}-x_{t-2}\right) .
\end{aligned}
$$

(trend-follower)

Define vector $n_{t}=\left(n_{1, t}^{y^{1}}, \ldots, n_{1, t}^{y^{N}}, n_{1, t}^{\pi^{1}}, \ldots, n_{1, t}^{\pi^{N}}\right)^{\prime}$, whose generic element $n_{1, t}^{v^{i}}$ denotes the fraction of agents using, at time $t$, the naive rule to forecast variable $v \in(y, \pi)$ in country 


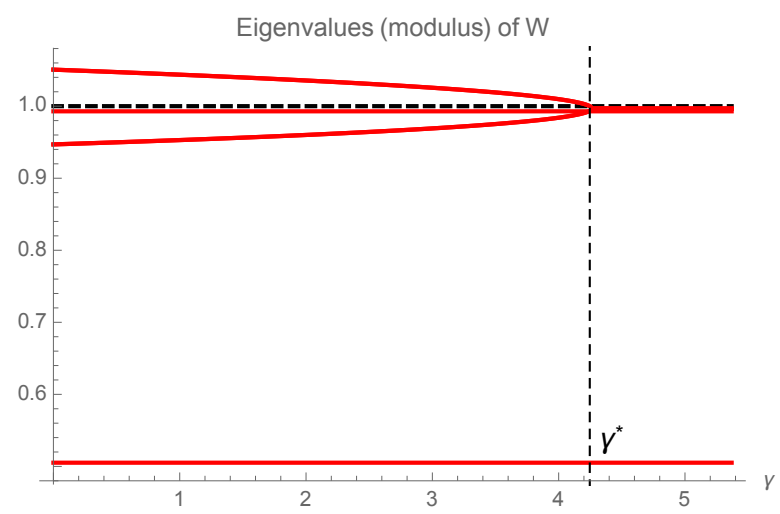

Figure B.2: Instability depending on $\gamma$

Notes: $\beta=0.99, \sigma=0.157, \kappa=0.001, \Phi_{\pi}=1.5, \Phi_{y}=0.5, N=3$. Parameter $\gamma$ is a convolution of the currency union's structural parameter $\sigma$ and the index of openness $\alpha \in[0,1]$, measuring the home bias in private consumption (see Appendix A for details). The range of $\gamma$ is thus obtained by letting $\alpha$ vary between 0 and 1.

$i \in(1, \ldots, N)$. Eq. (B.2) can then be rewritten as

$$
\begin{aligned}
x_{t} & =M \cdot\left(\operatorname{diag}\left(n_{t}\right) \cdot x_{t-1}+\operatorname{diag}\left(1-n_{t}\right) \cdot\left(x_{t-1}+\left(x_{t-1}-x_{t-2}\right)\right)\right) \\
x_{t} & =M \cdot\left(\left(\operatorname{diag}\left(n_{t}\right)+\operatorname{diag}\left(1-n_{t}\right)+\operatorname{diag}\left(1-n_{t}\right)\right) \cdot x_{t-1}-\operatorname{diag}\left(1-n_{t}\right) \cdot x_{t-2}\right) \\
x_{t} & =M \cdot\left(\left(I+\operatorname{diag}\left(1-n_{t}\right)\right) \cdot x_{t-1}-\operatorname{diag}\left(1-n_{t}\right) \cdot x_{t-2}\right) .
\end{aligned}
$$

Defining

$$
\begin{aligned}
& F\left(n_{t}\right)=M \cdot\left(I+\operatorname{diag}\left(1-n_{t}\right)\right) \\
& G\left(n_{t}\right)=-M \cdot \operatorname{diag}\left(1-n_{t}\right)
\end{aligned}
$$

we can rewrite system (B.8) as

$$
x_{t}=F\left(n_{t}\right) \cdot x_{t-1}+G\left(n_{t}\right) \cdot x_{t-2} .
$$

System (B.9) can be written in companion form as

$$
\left(\begin{array}{c}
x_{t} \\
x_{t-1}
\end{array}\right)=\left(\begin{array}{cc}
F\left(n_{t}\right) & G\left(n_{t}\right) \\
I & 0
\end{array}\right)\left(\begin{array}{c}
x_{t-1} \\
x_{t-2}
\end{array}\right)
$$

or more compactly as

$$
w_{t}=H\left(n_{t}\right) w_{t-1},
$$

with $w_{t}=\left(x_{t}^{\prime}, x_{t-1}^{\prime}\right)^{\prime}$. The vector of fractions $n_{t}$ evolves according to a switching model with no asyncronous updating $(\delta=0)$ and no memory $(\eta=0)$. Assuming that the fitness 
measure is given by squared forecast error, the generic element $n_{1, t}^{v^{i}}$ of vector $n_{t}$ evolves according to

$$
n_{1, t}^{v^{i}}=\frac{\exp \left(-\mu\left(v_{t-1}^{i}-v_{t-2}^{i}\right)^{2}\right)}{\exp \left(-\mu\left(v_{t-1}^{i}-v_{t-2}^{i}\right)^{2}\right)+\exp \left(-\mu\left(v_{t-1}^{i}-\left(v_{t-2}^{i}+\left(v_{t-2}^{i}-v_{t-3}^{i}\right)\right)^{2}\right)\right.}
$$

Using Eq. (B.10) we can thus write the updating of the $j$-th element of vector $n_{t+1}$ as

$$
e_{j}^{\prime} n_{t+1}=\frac{\exp \left(\mu\left(e_{j}^{\prime} H\left(n_{t}\right) w_{t-1}-e_{j}^{\prime} w_{t-1}\right)^{2}\right)}{\exp \left(\mu\left(e_{j}^{\prime} H\left(n_{t}\right) w_{t-1}-e_{j}^{\prime} w_{t-1}\right)^{2}\right)+\exp \left(\mu\left(e_{j}^{\prime} H\left(n_{t}\right) w_{t-1}-\left(e_{j}^{\prime} w_{t-1}+\left(e_{j}^{\prime} w_{t-1}-e_{j+2 N}^{\prime} w_{t-1}\right)\right)^{2}\right)\right.},
$$

where $e_{j}$ is the $j$-th coordinate vector and $j \in(1, \ldots, 2 N)$. Using Eqs. (B.10)-(B.11), we can write the full dynamical system as

$$
\begin{gathered}
w_{t}=H\left(n_{t}\right) w_{t-1} \\
n_{t+1}=f\left(n_{t}, w_{t-1}\right),
\end{gathered}
$$

where the $j$-th element of function $f$ is given by Eq. (B.11). ${ }^{1}$

Given that both heuristics deliver the same forecast in equilibrium, system (B.12) has a steady state given by

$$
\bar{w}=0 \quad \text { and } \quad \bar{n}=1 / 2 .
$$

The Jacobian of system (B.12) evaluated at the zero steady state is given by

$$
J=\left(\begin{array}{cc}
H(\bar{n}) & 0 \\
f_{w}(0, \bar{n}) & 0
\end{array}\right)
$$

The local stability properties of the zero steady state thus depend on the eigenvalues of $H(\bar{n})$. Figure B.3 depicts the eigenvalues of matrix $H(\bar{n})$ as functions of the economic integration parameter $\gamma$ for a currency union with $N=3$.

Obtaining an analytical expression for the eigenvalues of matrix $H(\bar{n})$ is quite complicated. It is however possible to show that when the modulus of $\lambda_{\max }$ is equal to one, i.e., when $\gamma=\gamma^{*}$, so does the modulus of an eigenvalue of $H(\bar{n})$. To see this, suppose that monetary policy satisfies condition (B.3), and compute matrices $F(\bar{n})$ and $G(\bar{n})$ in

\footnotetext{
${ }^{1}$ Note that defining $\tilde{n}_{t}=n_{t+1}$, system (B.12) can be written in standard form $\left(w_{t}, \tilde{n}_{t}\right)=F\left(w_{t-1}, \tilde{n}_{t-1}\right)$.
} 


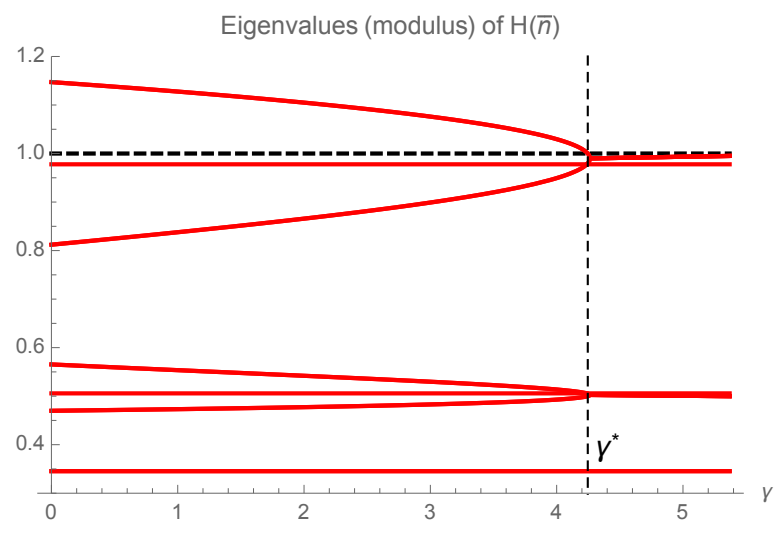

Figure B.3: Instability depending on $\gamma$

Notes: $\beta=0.99, \sigma=0.157, \kappa=0.001, \Phi_{\pi}=1.5, \Phi_{y}=0.5, N=3$. Parameter $\gamma$ is a convolution of the currency union's structural parameter $\sigma$ and the index of openness $\alpha \in[0,1]$, measuring the home bias in private consumption (see Appendix A for details). The range of $\gamma$ is thus obtained by letting $\alpha$ vary between 0 and 1.

$\bar{n}=1 / 2$ to get

$$
\begin{aligned}
& F(1 / 2)=M\left(I+\operatorname{diag}(1 / 2)=\frac{3}{2} M\right. \\
& G(1 / 2)-M \operatorname{diag}(1 / 2)=-\frac{1}{2} M
\end{aligned}
$$

Eigenvalues of matrix $H(1 / 2)$ thus satisfy

$$
\operatorname{det}\left(\begin{array}{cc}
\frac{3}{2} M-\lambda I & -\frac{1}{2} M \\
I & -\lambda I
\end{array}\right)=\operatorname{det}\left(\left(\frac{3}{2} M-\lambda I\right)(-\lambda I)+\frac{1}{2} M\right)=0
$$

where the first equality comes from the fact that matrices $I$ and $-\lambda I$ commute. For $\lambda=1$ to be an eigenvalue of $H(1 / 2)$, it must therefore hold that

$$
\operatorname{det}\left(-\frac{3}{2} M+I+\frac{1}{2} M\right)=\operatorname{det}(-M+I)=-1^{2 N} \operatorname{det}(M-I)=0,
$$

which is verified when $\gamma=\gamma^{*}$ for the largest eigenvalue of matrix $M$.

\section{B.2.4 VAR(1) Forecasts}

Consider a model where agents in country $i$ forecast domestic output gap and inflation based on a bi-variate VAR(1) model

$$
\left[\begin{array}{c}
y_{t}^{i} \\
\pi_{t}^{i}
\end{array}\right]=\left[\begin{array}{l}
a_{y}^{i} \\
a_{\pi}^{i}
\end{array}\right]+\left[\begin{array}{ll}
b_{y y}^{i} & b_{y \pi}^{i} \\
b_{\pi y}^{i} & b_{\pi \pi}^{i}
\end{array}\right]\left[\begin{array}{l}
y_{t-1}^{i} \\
\pi_{t-1}^{i}
\end{array}\right]+\left[\begin{array}{l}
e_{y, t}^{i} \\
e_{\pi, t}^{i}
\end{array}\right]
$$


where $\left(e_{y, t}^{i}, e_{\pi, t}^{i}\right)^{\prime}$ is a vector of perceived white noise errors. Using matrix notation, we can write the perceived law of motion (PLM) of variables in the currency union as

$$
x_{t}=A+B x_{t-1}+e_{t}
$$

where $A=\left(a_{y}^{1}, \ldots, a_{y}^{N}, a_{\pi}^{1}, \ldots, a_{\pi}^{N}\right)^{\prime}, e_{t}=\left(e_{y, t}^{1}, \ldots, e_{y, t}^{N}, e_{\pi, t}^{1}, \ldots, e_{\pi, t}^{N}\right)^{\prime}$ and

$$
B=\left[\begin{array}{cccccc}
b_{y y}^{1} & \ldots & 0 & b_{y \pi}^{1} & \ldots & 0 \\
\vdots & \ddots & \vdots & \vdots & \ddots & \vdots \\
0 & \ldots & b_{y y}^{N} & 0 & \ldots & b_{y \pi}^{N} \\
b_{\pi y}^{1} & \ldots & 0 & b_{\pi \pi}^{1} & \ldots & 0 \\
\vdots & \ddots & \vdots & \vdots & \ddots & \vdots \\
0 & \ldots & b_{\pi y}^{N} & 0 & \ldots & b_{\pi \pi}^{N}
\end{array}\right]
$$

Using the PLM in Equation (B.13), expectations conditional on the VAR(1) forecast models are

$$
x_{t+1}^{e}=(I+B) A+B^{2} x_{t-1} .
$$

The actual law of motion of variables in the currency union is then given by

$$
x_{t}=M(I+B) A+M B^{2} x_{t-1}+R \varepsilon_{t} .
$$

The mapping from the PLM to the ALM takes the form

$$
T(A, B)=\left(M(I+B) A, M B^{2}\right) .
$$

The fixed point of map $T$ given by $(\bar{A}, \bar{B})=(0,0)$ corresponds to the MSV rational expectations solution of the model as shocks are assumed to be unobservable. Evans and Honkapohja (2001) have shown that, when parameters in $A$ and $B$ are updated over time using OLS, local stability of the rational expectations equilibrium is governed by the E-stability principle. The equilibrium $(\bar{A}, \bar{B})=(0,0)$ is E-stable if it is locally asymptotically stable under the matrix differential equation

$$
\frac{d}{d \tau}(A, B)=T(A, B)-(A, B)
$$

Since the equation for $B$ is independent from $A$, we start by analyzing the stability of 
the equation

$$
\begin{aligned}
\frac{d B}{d \tau} & =M B^{2}-B \\
& =T_{B}(B)-B
\end{aligned}
$$

Following Evans and Honkapohja (2001) we have that the differential equation for $B$ is locally stable at $\bar{B}$ if all eigenvalues of the Jacobian

$$
D T_{B}(B)=B^{\prime} \otimes M+I \otimes F B
$$

have real part less than 1 . Since $D T_{B}(\bar{B})=0$, we have that the equation for $B$ is locally stable.

The differential equation for $A$ is instead given by

$$
\frac{d A}{d \tau}=M(I+B) A-A
$$

Provided that $B$ converges to $\bar{B}$, the equation for $A$ is locally stable when the eigenvalues of matrix $M(I+\bar{B})$ have real part less than 1 . Since $\bar{B}=0$, we have that the equilibrium $(\bar{A}, \bar{B})$ is E-stable when all eigenvalues of matrix $M$ have real part less than 1 .

As shown in Section B.2.1, provided that monetary policy satisfies condition (B.3), the real part of the largest eigenvalue of $M$ is less than one for $\gamma>\gamma^{*}$. Moreover, if $\gamma<\gamma^{*}$, the real part of the largest eigenvalue of $M$ is always larger than 1 independently on monetary policy. In other words, conditions for determinacy under rational expectations also ensure learnability of the equilibrium when agents use a bivariate VAR(1) to make forecasts and recursively update their predictions as new information becomes available.

\section{B.3 Determinacy and Mathematical Stability as Function of Trade Openness}

In the main text we present results on determinacy and mathematical stability in terms of the economic integration parameter $\gamma$. Figures B.4-B.6 report the same results of Figures $1-3$ in terms of the trade openness parameter $\alpha$. 

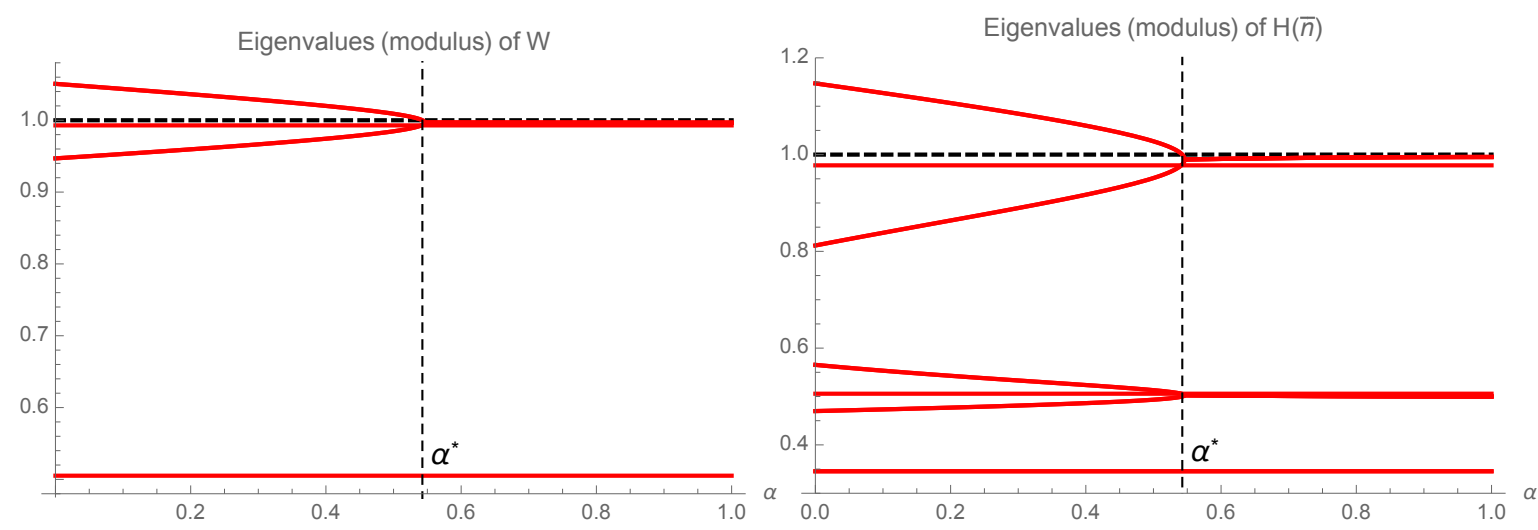

Figure B.4: Instability depending on $\alpha$

Notes: $\beta=0.99, \sigma=0.157, \kappa=0.001, \Phi_{\pi}=1.5, \Phi_{y}=0.5, N=3$.

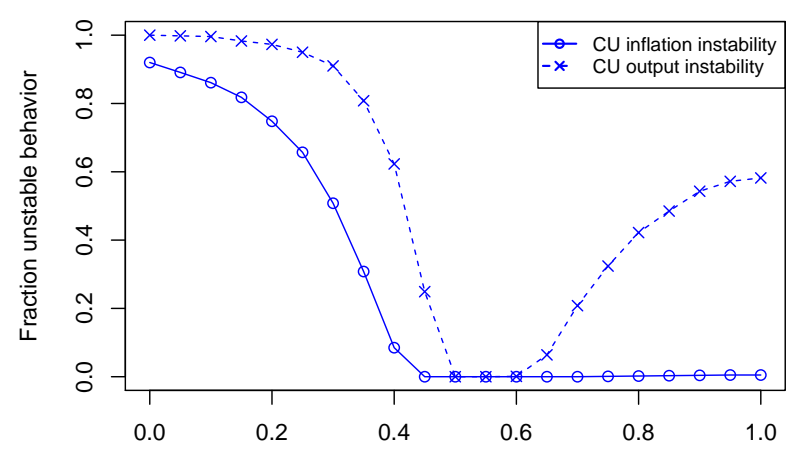

Figure B.5: Instability depending on $\alpha$

Notes: $\sigma=0.157, \kappa=0.001, \beta=0.99, \Phi_{\pi}=1.5, \Phi_{y}=0.5, \mathrm{sd}=0.1, N=3$.

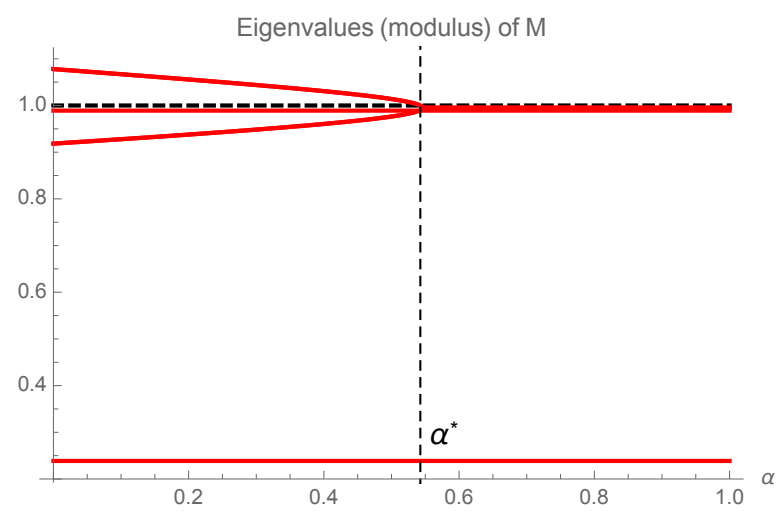

Figure B.6: Determinacy depending on $\alpha$

Notes: $\beta=0.99, \sigma=0.157, \kappa=0.001, \Phi_{\pi}=1.5, \Phi_{y}=0.5, N=3$. 


\section{B.4 Results of the Empirical Application with Different Parameter Values}

As discussed in Footnote 9, we also conduct the empirical application with different values of $\gamma$. These values of $\gamma$ are calculated with the estimates of $\sigma$ and proxies of the values of $\alpha$. These proxies of $\alpha$ are the averages of the export-to-GDP and importto-GDP ratios (obtained with Eurostat data for the year 2008). Table B.1 shows the parameter values for this exercise (corresponding to Table 2 in the main text) including the proxy for $\alpha$ used to calculate $\gamma$.

Table B.1: Parameter values (additional empirical application)

\begin{tabular}{lcccc}
\hline & $1 / \sigma$ & $\kappa$ & $\gamma$ & $\alpha$ \\
\hline Austria & 0.02 & 0.16 & -0.17 & 0.51 \\
Belgium & 0.04 & 0.20 & -0.20 & 0.79 \\
Finland & 0.14 & 0.08 & -0.07 & 0.43 \\
France & 0.01 & 0.12 & -0.48 & 0.29 \\
Germany & 0.01 & 0.08 & -0.16 & 0.41 \\
Italy & 0.03 & 0.01 & -0.11 & 0.27 \\
Netherlands & 0.03 & 0.01 & -0.19 & 0.66 \\
Spain & 0.01 & 0.12 & -0.46 & 0.28 \\
\hline
\end{tabular}

Notes: Parameter values for $1 / \sigma$ and $\kappa$ are annualized values derived from Dees et al. (2010). Values for $\gamma$ are derived from $\sigma$ and the reported proxy for $\alpha$. The values are rounded to the second decimal position.

Table B.2 shows the results with this calibration. The results are similar to those shown in Table 3 in the main text. 
Table B.2: Prediction Mean Squared Errors (additional empirical application)

\begin{tabular}{lcccccccc}
\hline & \multicolumn{3}{c}{ 4-country model } & \multicolumn{4}{c}{ 8-country model } \\
& \multicolumn{2}{c}{ Behavioral } & \multicolumn{2}{c}{ Rational } & \multicolumn{3}{c}{ Behavioral } & \multicolumn{2}{c}{ Rational } \\
& $\pi$ & $y$ & $\pi$ & $y$ & $\pi$ & $y$ & $\pi$ & $y$ \\
\hline Austria & & & & & 0.21 & 0.97 & 0.72 & 2.11 \\
Belgium & & & & & 0.39 & 0.24 & 1.54 & 1.08 \\
Finland & & & & & 0.23 & 1.82 & 1.20 & 5.16 \\
France & 0.22 & 0.26 & 0.79 & 1.12 & 0.22 & 0.27 & 0.79 & 1.12 \\
Germany & 0.23 & 0.65 & 0.77 & 3.23 & 0.23 & 0.65 & 0.77 & 3.23 \\
Italy & 0.24 & 0.29 & 1.00 & 2.10 & 0.24 & 0.29 & 1.00 & 2.10 \\
Netherlands & & & & & 0.37 & 0.40 & 1.73 & 2.07 \\
Spain & 0.57 & 0.41 & 2.40 & 1.60 & 0.57 & 0.43 & 2.40 & 1.60 \\
\hline Weighted average & 0.28 & 0.43 & 1.05 & 2.19 & 0.29 & 0.47 & 1.11 & 2.19 \\
\hline
\end{tabular}

Notes: The table contains mean squared errors of one-quarter-ahead predictions of inflation and output gap by the full behavioral model and the rational version of the model. Lower values imply better prediction performance. 